\title{
Adapting Social Impact Assessment to Flood Risk Management
}

\author{
Pablo Aznar-Crespo ${ }^{1, *(\mathbb{C})}$, Antonio Aledo ${ }^{1,2}$, Joaquín Melgarejo-Moreno ${ }^{2} \mathbb{( 1 )}$ and Arturo Vallejos-Romero ${ }^{3}$ \\ 1 Department of Sociology I, University of Alicante, Carretera San Vicente del Raspeig s/n, \\ 03690 Alicante San Vicente del Raspeig, Spain; antonio.aledo@ua.es \\ 2 University Institute of Water and Environmental Sciences, University of Alicante, Carretera San Vicente del \\ Raspeig s/n, 03690 Alicante San Vicente del Raspeig, Spain; jmelgar@ua.es \\ 3 Department of Social Sciences, University of La Frontera, Francisco Salazar Avenue, Temuco 01145, Chile; \\ arturo.vallejos@ufrontera.cl \\ * Correspondence: pablo.aznar@ua.es; Tel.: +34-96-590-3400 (ext. 2129)
}

check for

updates

Citation: Aznar-Crespo, P.; Aledo,

A.; Melgarejo-Moreno, J.;

Vallejos-Romero, A. Adapting Social

Impact Assessment to Flood Risk

Management. Sustainability 2021, 13,

3410. https://doi.org/10.3390/

su13063410

Academic Editors: Hugo Pinto,

Carla Nogueira and

Andrés Domínguez-Gómez

Received: 12 February 2021

Accepted: 16 March 2021

Published: 19 March 2021

Publisher's Note: MDPI stays neutral with regard to jurisdictional claims in published maps and institutional affiliations.

Copyright: (c) 2021 by the authors. Licensee MDPI, Basel, Switzerland. This article is an open access article distributed under the terms and conditions of the Creative Commons Attribution (CC BY) license (https:// creativecommons.org/licenses/by/ $4.0 /)$.

\begin{abstract}
In the context of climate change, a significant increase in the flood risk is expected, which may lead to an intensification of the social impacts of disasters. Social impacts significantly affect the recovery processes of individuals, social groups, and institutions in the medium and long term. Hence, the management of such impacts throughout the disaster life cycle is essential. International institutions and frameworks for disaster risk reduction have claimed the need to generate tools for the systematic assessment and management of social impacts of floods. Recently, an innovative line of research has emerged aimed at adapting social impact assessment (SIA), usually directed at the evaluation of planned interventions (programs, plans and projects), to the field of environmental disasters. In order to contribute to academic efforts in this emerging field, this paper puts forward, through a systematic literature review based on Preferred Reporting Items for Systematic Reviews and Meta-Analyses (PRISMA) criteria, an SIA methodological proposal for the identification, assessment and systematic management of the social impacts of flood events. This methodological proposal covers the three phases of the disaster cycle: (1) pre-event (preparedness), allowing the anticipation of potential impacts and supporting the proposal of preventive measures; (2) event (response), facilitating a strategic mobilization of resources and technical support towards previously identified critical disaster areas; and (3) post-event (recovery), evaluating the evolutionary dynamics of impacts, proposing measures to avoid their socio-territorial embedding and accelerating recovery processes. This tool is designed for strategic use by policy makers and managers responsible for flood risk management and regional development.
\end{abstract}

Keywords: social impact assessment; methodology; flood management; natural hazard; regional development

\section{Introduction}

In the current context of climate change, a sizeable increase in the frequency and magnitude of extreme climatic and meteorological events is foreseen, among them potentially catastrophic floods [1-4]. According to International Disaster Database figures [5], flood disasters affected a total of 1.65 billion people, caused around 122,000 deaths and produced damages calculated at a total of 563 billion US dollars throughout the world between 2000 and 2019. In the same period, there were a total of 3254 events of flooding across the planet, compared with 1389 for the 1980-1999 period [5]. The trend in the frequency and intensity of flooding occurrences is rising in most areas of the world [1], and this can bring with it significant changes in the size of the effects of these disasters [6,7]. In this sense, the flood disaster events represent processes with an increasing capacity to significantly affect the regional development dynamics of the exposed territories.

Some analysts have affirmed that this new level of risk can involve a significant intensification of the social impacts of flooding disasters [8-10]. According to the Associated 
Programme on Flood Management developed by the World Meteorological Organization [11], the social impacts produced by these events include, apart from the human losses, a range of short, medium and long-term changes and alterations that can affect means of subsistence, migratory processes, demographic dynamics, psychosocial health, relationships among and within communities, political and institutional reputations and regional development. The social impacts are highly complex, since they have multiple causes [12], include intangible factors that are difficult to quantify [13], are diffusely distributed and delimited in time and space [14] and, above all, are generated by an intricate combination of causes including hazardousness of the natural event, the adaptive conditions of people or exposure units and the social context [15]. Additionally, the long-term penetration of the social impacts in the territory can result in a reshaping of social actors' adaptive capacities, giving rise to acquired vulnerabilities and thereby conditioning the level of disaster risk in the face of future hazards [16].

The complexity and importance of the social dimension of disasters has gradually been recognised and argued for by bodies responsible for reducing disaster risks, thus fomenting its incorporation into disaster science. Orimoloye et al. [17], in an analysis of 853 articles on disaster risk reduction published between 1990 and 2019, found significant growth in social topics in the environmental disaster field. Thus, in the last thirty years flood risk management has incorporated new criteria and planning strategies, and these are now favouring a gradual transition towards integrated approaches based on the combination of structural and non-structural measures [18,19]. Apart from nature-based solutions, among the non-structural measures feature: initiatives to raise the awareness of risk amongst the population [20]; measures for promoting social actors' knowledge of selfprotection behaviours [21]; social communication systems for early warning in emergency situations [22]; and financial aid and insurance systems for repairing damages incurred [23]. These measures represent a process of transition towards a concept of adaptive flood management $[24,25]$, based on strengthening the social and institutional responses of the population and authorities throughout the life cycle of the disaster [26].

In the framework of this emerging integrated approach, a range of conceptual and methodological models aimed at analysing and addressing the social dimension of flood disaster risk have emerged, such as: (a) social capacity building [27], which enables the assessment and dissemination of knowledge on the social dimension of flood risk among social actors and public bodies; (b) participatory planning methods for flood risk management $[28,29]$, which strengthen awareness-raising around risk and social actors' knowledge of self-protection behaviours; (c) flood risk mapping, which on occasion includes social vulnerability variables [30,31]; (d) some renewed and adapted versions of the pressure and release model (PAR) developed by Blaikie et al. [32], which makes an in-depth analysis of the generative processes of social vulnerability in the face of disasters [14,33]; (e) social risk assessment, whose objective is to carry out an integrated disaster risk assessment [34,35]; and (f) the socio-hydrological approach, which allows us to reflect on the interactions between anthropogenic and biophysical processes in the generation of flood risk $[36,37]$. These tools enable us to produce knowledge and exhaustive information on the various components of flood disaster risk (hazard, exposure and vulnerability). According to the Intergovernmental Panel on Climate Change (IPCC) [1], these variables constitute the determinants of risk, which is the product of the combination of physical hazards and the vulnerabilities of the exposed elements. These determinants can be defined as [1]: (a) hazard, or extraordinary physical event with potential adverse effects on the exposure units; (b) exposure, or set of elements exposed or spatially close to the hazard spots; and (c) vulnerability, or susceptibility of the exposure units to suffer the impacts of hazards, although this concept can also include elements of resilience or adaptive capacity. Nevertheless, new initiatives have also emerged recently aiming to foment systematic understanding, not only of risk determinants itself, but also of the social impacts produced in situations of environmental disaster. 
Thus, the Sendai Framework for Disaster Risk Reduction 2015-2030, in the context of its first action priority, "understanding disaster risk," stipulates the need "to systematically evaluate, record, share and publicly account for disaster losses and understand the economic, social, health, education, environmental and cultural heritage impacts, as appropriate, in the context of event-specific hazard-exposure and vulnerability information" [38] (p. 15). To this end the World Bank [39], as part of its Global Facility for Disaster Reduction and Recovery (GFDRR) initiative, has recommended the application of tools such as social impact assessment (SIA from here on) to assess the social impacts caused by environmental disaster events. SIA is defined as "the processes of analysing, monitoring and managing the intended and unintended social consequences, both positive and negative, of planned interventions (programs, plans and projects) and any social change processes invoked by those interventions" [40] (p. 6). SIA is an assessment approach with an established track record in the professional and academic fields. It first appeared in the late 1960s, when the USA National Environmental Policy Act (NEPA) required an environmental impact assessment to study the social effects of planned interventions [41]. The first SIA were applied to dam projects at the beginning of the 1970s [42,43], although in time their use has become more widespread in mining, especially in countries such as Canada and Australia, where such projects are sometimes carried out in indigenous people's lands [44,45]. During the 1980s and 1990s, the first seminal SIA studies emerged [46-50], laying down the conceptual and methodological foundations on which the discipline was built. The development of the field has led scholars to reflect on the ability of SIA not only to assess impacts from the technical point of view, but also to influence management as a governance tool. Thus, Esteves et al. [51] distinguish between the social impact statement and social impact management. The former does not have the objective of influencing the design of the intervention planned, but simply of measuring its direct impacts and guaranteeing that it will be approved. While this approach has prevailed in SIA practice up to now, lately this paradigm has been widely criticised for its scant effects on the governance of interventions and its limited scope in social and environmental sustainability [52,53]. Management-oriented SIA, however, in addition to identifying and assessing impacts, aims to put forward mechanisms for managing them. This second approach promotes the participation of social actors in the impact identification and assessment processes, recognises the uneven distribution of impacts, incorporates a holistic and diachronic view of their generative processes and seeks a socially balanced distribution of the costs and benefits of interventions $[53,54]$. Thus, SIA can be seen as a social innovation tool that is capable of monitoring and managing the risks and regional development processes set in motion by the actions of managing and recovering from social impacts $[55,56]$.

Recent studies have proposed conceptual and methodological frameworks for adapting SIA to the characteristics of the social impacts of disaster events stemming from natural hazards [11,34,57-60]. According to some analysts [56,61], SIA-specifically its management version-enables the strengthening of the post-disaster phase through the systematic monitoring of social impacts and mechanisms for managing them. In the absence of such monitoring systems, social impacts, due to their high complexity and the difficulty of predicting them, tend to emerge as unforeseen, hard-to-manage effects hindering the recovery process [62-64]. Thus, the identification and assessment of the social, spatial and temporal distribution of social impacts represents a strategic information input enhancing the process of decision-making for the design of effective response mechanisms to the social effects of disasters [65]. Moreover, other analysts advocate the ex-ante use of SIA as an instrument for anticipating the occurrence of potential impacts and supporting the design of preventive measures aimed at strengthening the adaptive capacity of vulnerable social groups and creating highly contextualised intervention procedures [66,67]. De Risi et al. [68] take this further, advocating the use of SIA for estimating the social impact of disaster risk reduction policies and determining their degree of feasibility, acceptability and social utility.

SIA is a far-reaching tool with great potential for unravelling the complexity of social impacts, systematising knowledge of them, and devising ways of integrating them in 
risk planning. Some analysts, however, acknowledge that the development of SIA in the environmental disaster field is incipient and still has a long way to go in both concepts and methodology [6,69-71]. This study was able to confirm these views through a systematic literature review on social impacts and floods (see Section 3). The review revealed that, although the social impacts of disasters have frequently been analysed, in most cases these are assessments made from outside the structure and objectives of SIA. In other words, these studies do not follow the SIA process of identifying and assessing impacts in order to propose impact management measures. The adaptation of SIA to the social impact assessment of disasters is an emerging and promising field, which requires new efforts to be made in readjusting both concepts and methodology.

In the context of the opportunities emerging from the integration of SIA into the disaster field, this study aims to: (1) contribute to endeavours to adapt SIA concepts and methodology to the flood field; and thereby (2) to take the social impact analysis of these disasters a step beyond the post-disaster studies aimed solely at evaluating the direct social effects. Thus, the objective of this paper is to offer a methodological proposal to SIA for the analysis and proactive management of the social impacts of flood events. Two main sources of information were used in the design of this methodological proposal. Firstly, the SIA methodological structure devised, validated and implemented by the International Association for Impact Assessment (IAIA) was used as a framework to adapt SIA to the field of flood disasters. Secondly, a systematic literature review on social impacts and floods was performed, enabling us to identify the conceptual and methodological opportunities offered by SIA in this field and to determine the concepts, methods and techniques most frequently applied in the field, which were then used as models to design the different phases of the SIA methodological proposal put forward in this study. This methodological proposal, with a pre-eminently practical and proactive bent, provides a tool designed for strategic use by policy makers and technical managers responsible for flood risk planning and regional development.

\section{Conceptual Principles of SIA Adaptation}

The main aim of this methodological proposal is to strengthen flood risk management by putting forward mechanisms for (a) systematically identifying social impacts, and (b) giving sound foundations to the design of options for preventive management and effective response. To this end, the proposal is based on four principles governing the scientific approach to social impact analysis and assessment, namely: constructivism, social participation, diachrony and environmental justice values; all of these aligned with the SIA management approach [51]. According to Domínguez-Gómez [72], these four principles are essential for (a) unravelling the high complexity of social impacts, and (b) supporting SIA proposals by giving them real scope in social and environmental sustainability. Below, the characteristics of these four principles are outlined within the framework of SIA adapted to flood risk management (FRM from here on):

- Constructivism: this approach, in addition to acknowledging the physical dimension of the impacts caused by flooding, embraces the subjective nature of the impact experience; that is, how social actors individually perceive the meaning of the consequences of the disaster. Thus, this paper concurs with Vanclay's [73] (pag. 191) definition of a social impact: "social impact refers to the impacts actually experienced by humans (at individual and higher aggregation levels) in either a corporeal (physical) or cognitive (perceptual) sense."

- Participation: in recognising the subjective nature of the meaning of impacts, this study also advocates the broadening of the assessing community by the inclusion of social actors in impact identification and assessment. This participatory format, widely adopted in SIA [74-76], enables us to (a) capture the diversity of perspectives on impacts, and (b) empower social actors for a deeper knowledge of flood risk, disaster impacts and recovery paths [65]. 
- Diachrony: this approach sees social impacts as the result of a complex combination of generative and modulating forces responding to long-term social, economic and cultural processes [77]. These processes shape (a) socio-territorial development models, which determine exposure to flood risk, and (b) drivers of social vulnerability, on the basis of which the adaptive conditions of exposure units are built $[78,79]$. This causative complexity also affects the evolution through time of social impacts, which, far from being static, can undergo long-term transformations and reshape the population's adaptive conditions, thereby creating acquired vulnerabilities in the face of new hazards [16] and setting off processes of social change [80].

- Socio-environmental justice: disaster impacts, since they depend directly on social, economic and cultural structures, have an uneven social distribution in line with social class differences [81], ethnicity [82] and gender [83]. These distinctions require the inclusion and recognition in SIA of an ethical perspective oriented towards socially balanced impact management, particularly sensitive to vulnerable social groups and including environmentally sustainable criteria [54].

\section{Methods}

Two different information sources were triangulated in the design of this SIA methodological proposal for FRM. Firstly, the methodological structure proposed and validated by the IAIA for assessing the social impacts of planned interventions was adopted. This comprises 4 main phases [84]: (1) scoping and profiling (or baseline study), aimed at studying in depth the features of the force/agent of change and the adaptive conditions of the exposed community; (2) identifying, analysing and assessing the social impacts; (3) formulating strategies for impact management; and (4) designing impact monitoring programs. According to the specialised literature review by Domínguez-Gómez et al. [85], this structure is the most common way that SIA practice is set out, although it may involve small variations in the names of the phases or in the distribution of their contents.

Secondly, through the Preferred Reporting Items for Systematic Reviews and MetaAnalyses (PRISMA) [86], we carried out a systematic literature review on social impacts and floods (Figure 1) with the two-fold objective of identifying the research concepts, methods and techniques used in the field and of orienting the adaption of the contents of SIA to this field. To this end, a systematic search of scientific documents on the topic was carried out in the Web of Science (WoS) and Scopus using the following keyword algorithm:

$$
\begin{aligned}
& \left(\mathrm{TI}=\left(\text { flood* OR disaster* OR "natural hazard" }{ }^{* \prime}\right)\right) \text { AND }(\mathrm{TS}=(\text { "social impact" OR } \\
& \text { "societal impact" } \left.{ }^{* \prime}\right) \text { AND }\left(\text { TS }=\left(\text { assess }^{*} \text { OR evaluat }{ }^{*} \text { OR diagnos* OR analy }{ }^{*}\right)\right. \text { ) }
\end{aligned}
$$

where: $\mathrm{TI}=$ title and TS $=$ topic (abstract and keywords).

As this algorithm shows, three keyword fields and various search resources (conceptual and lexical synonyms and truncation) were used to ensure bibliometric inclusiveness while at the same time correctly delineating the area of research. The first field contained keywords related to the natural threat under study, although others relating to disasters were included in order to cover relevant documents with a more general scope. The keywords in this field were searched for in the document titles, thus ensuring the appropriate delineation of the review around disasters caused by flooding. The second field was made up of keywords referring to social impacts. Since it emerged that these keywords did not normally appear in document titles, it was decided to search the abstracts and keywords (topic) instead. The third field was also applied to the document topics and included keywords relating to analytical and/or assessment criteria in order to yield documents whose contents were not only conceptual but also methodological. Apart from the keywords, the following inclusion criteria were used: any type of document (document type) published in English (language) in any Web of Science and Scopus database (database) from 1864 to the present day (timespan). A total of 384 results were obtained from these criteria. After reviewing the title of the documents, 162 were deleted due to repetition, i.e., because they appeared simultaneously in the two databases. Out of the remaining 222 records, and 
after reviewing the abstracts of the documents, 113 were deleted because they did not directly pertain to the field of research analysed. The remaining 109 records were then reviewed in greater depth, discarding 31 for insufficient affinity with the research topic and finally obtaining a sample of 78 documents. Additionally, through snowball sampling, 11 further documents of interest were found among the list of bibliographical references of the reviewed documents. Hence the final sample of scientific documents amounted to 89 (n). In addition, and complementarily, a search was undertaken in the grey literature, i.e., theoretical and technical documents of diverse origins (public institutions, research centres, non-governmental organizations, foundations, etc.) which have not been produced or distributed by publishing houses or commercial brands. This search made it possible to identify 21 interesting documents, which were used together with the sample of scientific documents during the process of adapting the SIA methodological proposal presented in this paper.

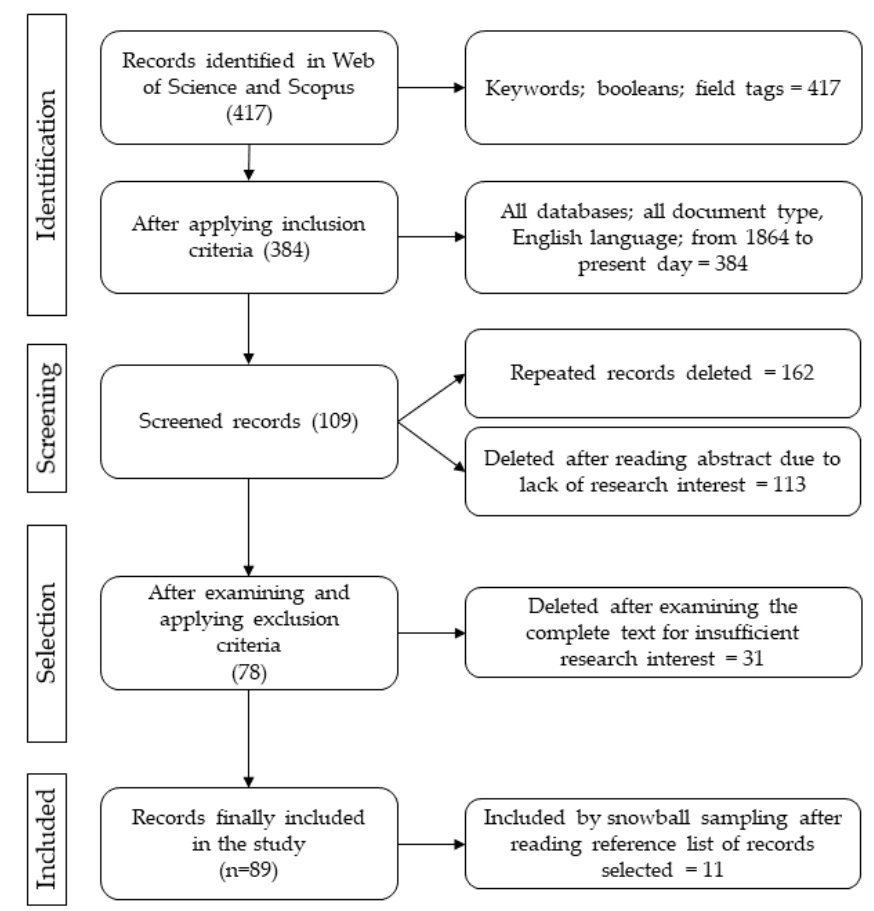

Figure 1. Flowchart of the systematic literature review based on Preferred Reporting Items for Systematic Reviews and Meta-Analyses (PRISMA) criteria.

A meta-analysis of the collected documents was then carried out in order to: (1) describe the basic thematic features of the sample of scientific documents; and (2) identify the analytical and methodological concepts and procedures compatible with the SIA structure put forward by the IAIA.

On the one hand, of the total number of scientific documents analysed $(n=89), 49$ $(55.1 \%)$ were research papers applied to case studies and $40(44.9 \%)$ were non-applied articles (particularly proposals of conceptual and methodological frameworks and review articles). Although each document in isolation dealt with at least one methodological factor compatible with SIA, only 21 (23.6\%) discussed the integration of SIA into the flood disaster field. Of these 21 documents, 17 were from the non-applied group and only 4 from the applied research. Further, the following conclusions were drawn from the topic analysis of the sample:

- Development of the publications: the scientific literature on social impacts and disasters is an emerging research field. A percentage of $62.9 \%$ of the scientific documents in the sample were published between 2016 and the present, with a clear tendency towards growth. These data showed the promising nature of the research field. 
- Concept of social impact: the topics most often discussed in the analyses applied to social impacts and disasters were: deaths $[87,88]$, effects on health $[89,90]$; infrastructure service destruction [91,92]; disruption of normal life [93,94]; and damages to economic activities $[95,96]$. Other studies, with lower frequency, encompassed additional areas of social impact with greater depth, which included intangible factors such as psycho-social effects $[97,98]$, trust towards institutions $[99,100]$ and flood risk awareness [101,102].

- Methodological style: the applied documents mainly consisted of assessments of specific impact areas. Studies evaluating a range of different impact areas from a holistic perspective were uncommon $[59,88,103]$. Further, the review did not find applied studies directly adopting the complete framework, objectives and methods of SIA. Gurtner [104], in fact, remarks on the difference between SIA applied to disasters, consisting of social impact assessments aimed at formulating management measures, and post-disaster studies, which are mostly estimations of the social effects of disasters. In contrast, some non-applied documents were found directly indicating the opportunity represented by using the SIA framework for assessing and managing the social impacts of flooding $[11,39,57,58,65,66]$.

- Challenges and opportunities: some documents discussed the challenges and opportunities involved in adapting SIA methods to the disaster field. On the side of challenges and barriers, factors such as the deficient legislation on SIA [71] or the need to develop social evaluation criteria that go beyond traditional econometric conceptions of impacts [105] were highlighted. Turning to opportunities, some analysts emphasised the production of materials specifically for adapting SIA methods to disasters in order to catch the attention of the scientific community and, in particular, flood risk managers $[58,59,71]$.

On the other hand, the meta-analysis of the sample also consisted in an in-depth review of the documents, divided into three stages. First, a selective document review aimed to identify and list concepts and methodological procedures (e.g., impact classifications, procedures for studying the context, methods for analysing degrees of flood danger, assessment criteria and techniques, seminal concepts regarding disasters, etc.) that were compatible with the SIA methodological structure put forward by the IAIA. Second, an analysis of the elements of information obtained was performed, and these were grouped and classified according to the SIA phases with which they might be compatible, thereby giving rise to the SIA structure of this study (Figure 2). Lastly, taking the SIA structure resulting from the previous step as a model, the information contents were structured and written up in the form of a methodological proposal. This process, apart from using the information obtained from the meta-analysis of the document sample, also drew on the authors' methodological background in the conceptual field of SIA [54,106], in its application to a range of international projects $[16,107-111]$ and in the field of socio-environmental disasters $[15,112-115]$.

\begin{tabular}{|c|c|c|c|c|}
\hline Phases & \multicolumn{3}{|c|}{ Social Impact Assessment for flood risk management } & \\
\hline $\begin{array}{l}\text { 1. Baseline } \\
\text { study }\end{array}$ & $\begin{array}{l}\text { 2. Stakeholder } \\
\text { analysis }\end{array}$ & $\begin{array}{l}\text { 3. Impact } \\
\text { analysis }\end{array}$ & $\begin{array}{c}\text { 4. Impact } \\
\text { management }\end{array}$ & \\
\hline 1.1. Case review & $\begin{array}{l}\text { 2.1. Stakeholder } \\
\text { identification }\end{array}$ & 3.1. Impact identification & 4.1. Option formulation & \\
\hline $\begin{array}{l}\text { 1.2. Natural hazard } \\
\text { analysis }\end{array}$ & \multirow{2}{*}{$\begin{array}{l}\text { 2.2. Stakeholder } \\
\text { assessment }\end{array}$} & 3.2. Impact assessment & $\begin{array}{l}\begin{array}{l}\text { 4.2. Feasibility } \\
\text { assessment }\end{array} \\
\end{array}$ & Phases \\
\hline $\begin{array}{r}1.3 \text { So } \\
\text { at }\end{array}$ & & 3.3. Impact prioritization & 4.3. Impact monitoring & Sub-p \\
\hline
\end{tabular}

Figure 2. Methodological process of the social impact assessment (SIA) applied to flood risk management (FRM). Source: created by the authors. 


\section{SIA Methodological Proposal for Flood Risk Management}

In this section, we present the proposal for the methodological adaptation of SIA to the assessment and management of the social impacts of floods. Although the social impacts of flooding have been discussed often in post-disaster studies and damage estimates, this promising methodological proposal aims to contribute to emerging endeavours to develop and adapt the SIA framework of the identification, assessment and management of social impacts to the field of flood disasters. To this end, and bearing the methodological opportunities identified in the systematic literature review in mind, a step-by-step SIA methodological proposal is offered that is specifically adapted to the nature of the object of flood studies. The objective underlying this proposal is to attract the attention of both the scientific community and managers responsible for the application of measures for flood disaster risk reduction.

This methodological proposal is divided into interdependent phases, which are (Figure 2): (1) the setting and its different components are analysed in a baseline study; (2) the set of social actors participating in the management or experience of flood risk is analysed; (3) the social impacts are identified and their characteristic effects assessed; (4) management options for reducing flood disaster risk are formulated, their social, environmental and economic feasibility are evaluated, and monitoring systems for tracking impacts and compliance with agreements are designed. Below, we explain in more depth the methodological phases of this methodological proposal to SIA for flood disaster risk.

\subsection{Phase 1: Baseline Study}

The goal of the baseline study is to analyse in detail the three basic components of the processes giving rise to the impacts: (a) the characteristics of the natural hazard; (b) the adaptive capacities of the exposure units; and (c) the social context. The baseline study sets up an analytical reference framework for the setting of the risk studied, thus ensuring the contextual suitability of the subsequent SIA phases. This baseline study is composed of three stages (Figure 3): (a) review of past flood experiences, similar settings and the specialised literature; (b) natural hazard analysis; and (c) analysis of the social context and exposure units.

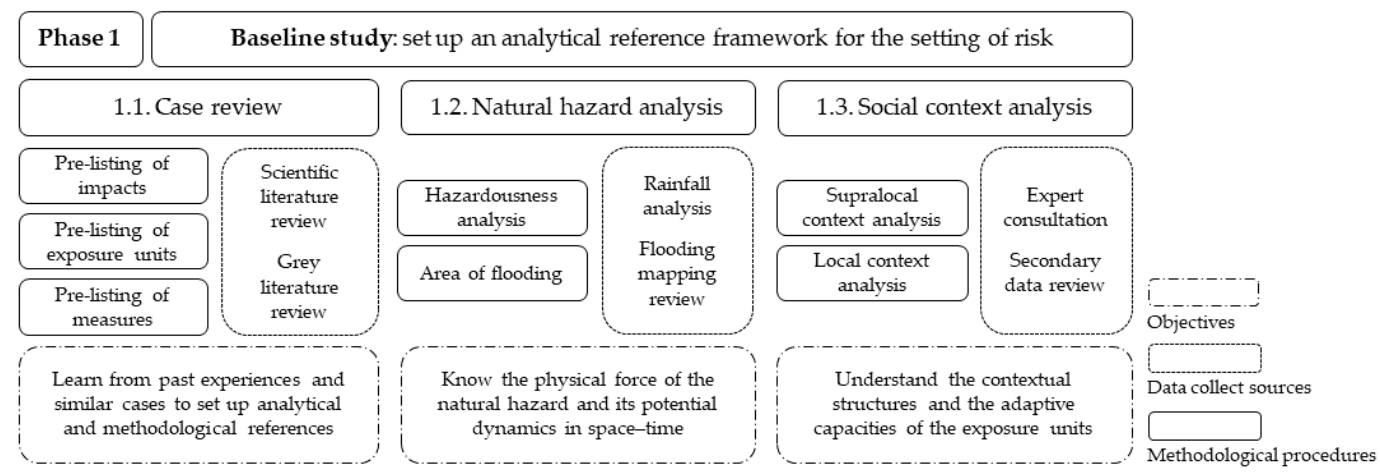

Figure 3. Methodological process of the baseline study. Source: created by the authors.

\subsubsection{Case Review}

The case review is the search, in scientific sources and the grey literature, for previous flood disaster events in the area of influence of the case study, as well as similar study cases or SIA experiences. These reference cases enable us to estimate, on the basis of past experience, the flood disaster risk in a specific society and territory, and to identify impacts, exposure units and the most frequent management measures adopted. Nevertheless, any conclusions reached from the analysis of reference cases must be treated as complementary and direct extrapolations must be avoided. The influence of climate change on rainfall patterns has increased the risk of flooding in some regions, thus pushing up levels of 
uncertainty in comparative analysis. The three most important outcomes of the case review are:

- Pre-listing of impacts: the set of impacts most commonly caused by the disaster events analysed.

- Pre-listing of exposure units: the set of territorial unities and social groups belonging to them most often affected by disaster events.

- $\quad$ Pre-listing of management measures: the set of measures and actions generally applied in management processes for reducing disaster risk.

To obtain these outcomes, some studies on social impacts and floods have recommended reviewing and analysing information from specialised disaster databases such as the EM-DATA [99], local newspapers [116], historical archives on past disasters [117] and the scientific literature on case studies [118].

\subsubsection{Natural Hazard Analysis}

Natural hazard is the force or stress stimulus that produces changes in the biophysical environment or foci of effects. The combination of the hazard magnitude and the adaptive capacity of exposure units (vulnerability) yields the intensity of the impacts and determines the possibility of a disaster occurring. Hazard analysis consists in making a detailed description of the characteristics and hazardousness of flooding in the spatial and temporal field of the region studied. Thus, this phase of the SIA has two sections or stages: (a) analysis of the hazardousness, and (b) analysis of the area and time scale of its effects.

Firstly, to analyse the hazardousness it is necessary to consult the information available on rainfall data series and flood mapping. However, when information on a specific area is insufficient or out-of-date, or the area studied is highly specific and requires the use of more detailed scales, the SIA team may choose to carry out flooding studies. For this reason, and given that FRM is a complex, multidimensional phenomenon, SIA teams should be multidisciplinary and embrace the greatest possible diversity of conceptual and technical forms of knowledge. For the hazardousness analysis, information must be compiled on:

- Rainfall pattern: the analysis of historical series of rainfall data in the area studied [119]. Additionally, changes in the rainfall pattern due to climate change should be estimated. Any structural changes in the rainfall pattern can result in the loss of statistical predictability over the longer term [120]. These changes can also mean that we should call into question the temporal references on the basis of which the periodicity of torrential rains has been estimated and structural protection measures designed. The study of return periods $(\mathrm{T})$ should be made with all due caution and always bearing in mind an inevitable level of uncertainty.

- Probability of flooding: the analysis of the hydrographic characteristics of the river basin and the estimation of possible flooding levels (sub-surface permeation and surface run-off). At this stage it is necessary to analyse the influence of anthropogenic processes on increases in danger levels, particularly in relation to changes in land use [121]. The main outcome should be a map of the areas at risk of flooding in the region studied and the categorization of levels of intensity in each area.

Secondly, a study of the area of flooding must be carried out. The main potentially affected areas must be delineated, i.e., the territorial units where the different levels of rainfall and flooding are distributed. To achieve this, consulting and analysing any available flood maps is recommended [122]. The study of flood maps is useful for estimating the spatial distribution of effects during a flood event. In the course of such events, flooding levels tend to have different effects across the territory, with at least two distinct effect areas:

- Primary space: the enclave where the highest level of flood hazard is found, or the ground zero of the event. The flooding level in a geographical area is usually determined by the levels of rainfall records in its immediate surroundings, especially for flashfloods. However, flooding caused by river overflow also depends on the water flowing in from the whole of the relevant river basin. In short, the primary 
spaces are those undergoing the highest levels of flooding during an event; thus, they normally experience the highest-intensity impacts, although the severity of effects is also contingent on the vulnerability of the exposure units.

- Secondary space: the rest of the geographical points in the river basin area where the flood event takes place. These are spaces that (a) have hydrographic influence over the flooding levels of the primary space, and (b) are indirectly affected by the hydrological effects of an event (i.e., where levels of flooding are lower). Secondary spaces tend to undergo impacts of low to moderate intensity, except in cases where vulnerability is very high.

\subsubsection{Social Context Analysis}

The context refers to the total set of structural forces of a social, economic and cultural nature governing the ideological and regulatory workings of the overall system. The social context mediates the relationship between the natural hazard and the exposure units as a modulating force in the generative process of impacts $[15,16,77]$. The social context analysis consists in the identification of the structural forces and conjunctural factors making up the contextual framework on two levels: the local and the supralocal. The supralocal level represents the set of macrostructures that (a) underpin the socio-economic models on which the living conditions of the population are based, and (b) influence the ideological orientation of the political and institutional management models. In the FRM field, supralocal forces must be analysed in the following areas:

- Risk culture: the system of values, meanings and behaviours related to the representation of, knowledge of and response to flood risk of the population and institutions responsible for management. Risk culture may be determined by historical exposure to floods, past disaster experiences, or institutional promotion of risk awareness and knowledge [123,124].

- Risk governance: the orientations and approaches to management related to hydrological planning for flooding. In this area, the political contexts of decision-making for risk planning should be analysed. It is particularly important to study how the exposed territories implement integrated management mechanisms, i.e., how the management bodies articulate structural and non-structural FRM solutions and involve the social actors in the design and management processes of these measures [125].

- Socio-economic frameworks: in general, the social, cultural and economic macroforces governing the systems of socio-economic production and exchange on which the living conditions of the population are based [126].

Turning to the local level, this refers to the infrastructural conditions that directly shape the adaptive capacities of the exposure units faced with flood disasters. In performing the local context analysis, we can deploy the concept of social vulnerability, since this encompasses the whole set of social, economic, political and cultural conditions determining the capacity of people, groups and systems to respond to the negative consequences of stress events and recover from the changes produced by them [127]. Rufat et al. [128], in a review of 125 articles on social vulnerability with regard to flooding, recommend analysing the following categories of social vulnerability:

- Demographic characteristics: age, race, ethnic background, family background, gender and language/s spoken.

- Socioeconomic status: income and purchasing power, employment, education and social capital.

- Health: access to health services and health conditions of the population.

- Land tenure: property structure, regulation of human settlements, housing quality, property markets (renting and purchasing) and insurance systems for housing and goods.

- Neighbourhood characteristics: essential urban services and transport infrastructures. 
- Risk perception: risk awareness and culture, previous experiences of flood events, knowledge of self-protection measures and trust in public institutions among the local population.

\subsection{Phase 2: Stakeholder Analysis}

In SIA, the concept of the stakeholder refers to any individual, group or institution that is directly or indirectly affected by the impacts of an activity. The objective of the stakeholder analysis in FRM (Figure 4) is to identify and characterise the individuals and groups - or their representatives-involved in governance and having some relationship of responsibility, experience or interest in the flood disaster risk and its resulting impacts.

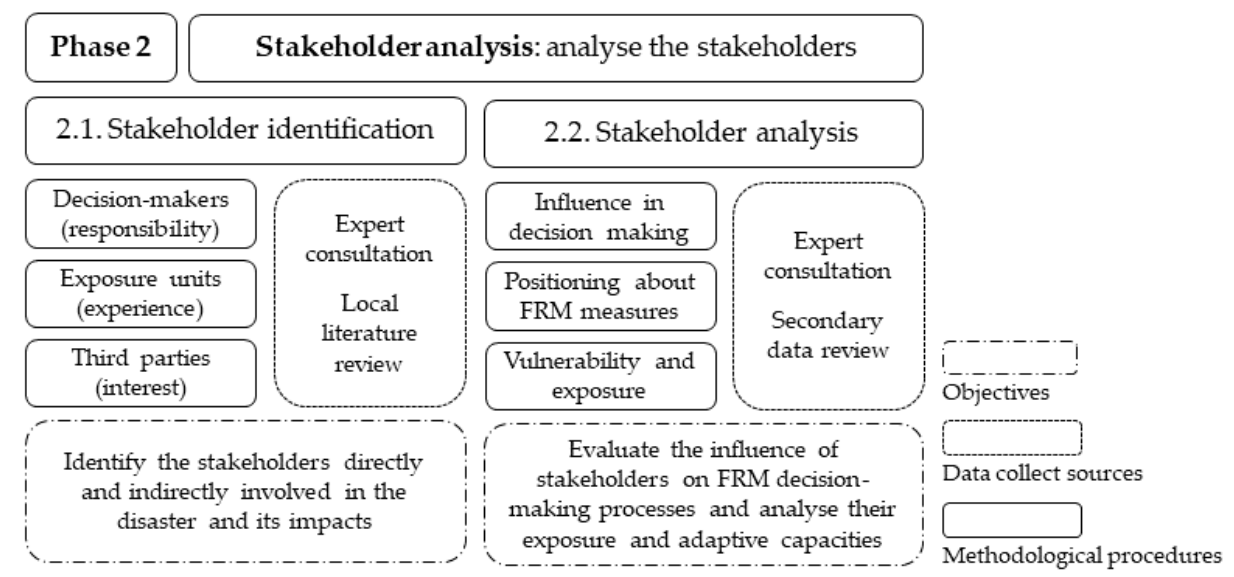

Figure 4. Methodological process of the stakeholder analysis. Source: created by the authors.

These three types of relationship in turn characterise the three types of stakeholder that should be identified in an SIA applied to FRM. These three groups, the most normally used in the specialised literature [129], are:

- Decision-makers (responsibility): the institutional actors and authorities responsible for designing and implementing FRM measures and actions. In addition to their relationship of responsibility, the decision-makers can also undergo some indirect impacts in the post-disaster phase (e.g., reputational costs due to inefficient management of the disaster).

- Exposure units (experience): the people, means of subsistence, services, environmental resources, infrastructures and goods in a position of exposure that directly suffer the impacts of the disaster.

- Third parties (interest): other social actors, such as NGOs, water industry companies or academics, that participate indirectly in FRM and have some interest in the risk, either due to its economic effects (e.g., from the design and application of structural measures) or stemming from a political (e.g., actions in favour of a change in management paradigm) or scientific (e.g., research lines) motivation.

With the aim of identifying and characterising the stakeholders involved in the governance of the flood risk, this phase of the SIA is divided into two parts: the compilation of the list of stakeholders and its subsequent assessment. Firstly, using the information gathered in the baseline study, the knowledge garnered by the SIA team, and the collection of primary information from key informant interviews, a list of stakeholders should be drawn up to include the main actors in the three relevant groups and their corresponding subgroups: (a) decision-makers, (b) exposure units (human, environmental and material) or their representatives, and (c) third parties. When compiling this list, the researchers should neutralise the imbalances inherent in the social structure, avoiding under- or over-representation of any stakeholder for social, political or economic reasons (the most powerful, best represented, most active, etc.). Once the list of stakeholders is completed, 
the next step is to assess their socio-political and adaptive capacities [130]. This analysis should encompass the following two areas:

- Influence: the degree of involvement that each stakeholder has in the flood risk governance processes to influence the design and implementation of measures and actions [131]. The assessment of influence can be applied to all stakeholders (Table 1). Beyond the direct or indirect experience of impacts, all stakeholders can exert influence on the FRM decision-making processes.

- Vulnerability and exposure: the degrees of sensitivity $(-)$ and adaptive capacity $(+)$ of each stakeholder in responding to the effects of the flood event and recovering from its negative impacts [1]. To carry out this analysis, different conceptual frames can be used, such as those on social vulnerability to disasters [128] or the Community Capitals Framework [132]. Likewise, the exposure of each stakeholder must be analysed in terms of (a) occupation of flood areas and (b) proximity to safe areas and protection services. Given that the exposure and vulnerability assessment is related to adaptive capacity elements, it should only be applied to stakeholders classified as exposure units (Table 1).

Table 1. Example of a list of stakeholders. This list should be completed with all identified stakeholders $(\mathrm{DM}=\mathrm{decision}-$ makers; EU = exposure units; TP = third parties). Source: created by the authors.

\begin{tabular}{cccccc}
\hline Stakeholder & Code & Group & Influence & Exposure & Vulnerability \\
\hline Regional administration & A & DM & 5 & - & - \\
Suburban population & B & EU & 2 & 5 & 4 \\
Town council & C & DM & 5 & - & - \\
Downtown population & D & EU & 3 & 3 & - \\
Hydraulic companies & E & TP & 1 & 2 & 5 \\
Short-stay tourists & F & EU & 1 & 5 & - \\
Migrant population & G & EU & 3 & - & $(\ldots)$ \\
NGOs & H & TP & $(\ldots)$ & $(\ldots)$ & \\
$(\ldots)$ & $(\ldots)$ & & & & \\
\hline
\end{tabular}

The combination of these variables determines the structural position of each stakeholder to (a) face the impacts of the event and (b) participate in the FRM decision-making process. This governance environment has been termed the sociospace of conflict by Aledo [108], referring to stakeholders' mobilisation of political and discursive strategies based on their social, political, economic and cultural capital and aimed at building relationships of alliance or opposition among the interested parties and attaining an advantageous position in the FRM decision-making process.

\subsection{Phase 3: Impact Analysis}

The objective of this phase is to make an exhaustive in-depth analysis of the social impacts undergone by the exposure units. Obtaining the results of this phase, however, is not the ultimate purpose of this methodological proposal, as its function is not an impact measurement per se, but instead the identification of targets and strategic paths for reducing flood disaster risk. This phase is divided into two parts (Figure 5): (a) impact identification and (b) impact assessment. 


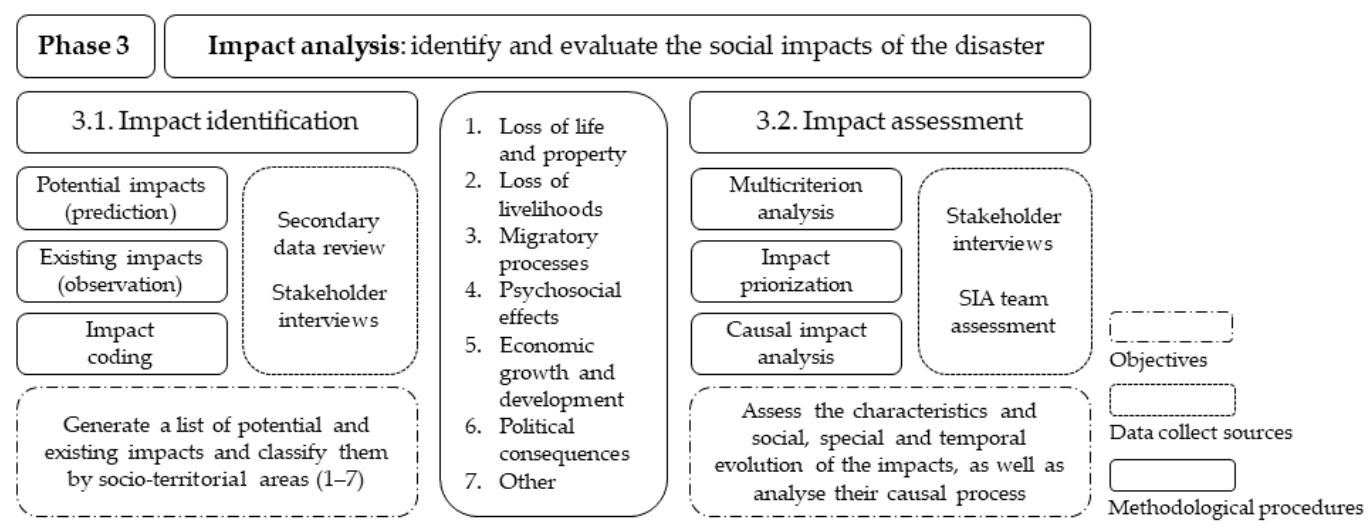

Figure 5. Methodological process of the impact analysis. Source: created by the authors.

\subsubsection{Impact Identification}

The objective of this stage is to identify the social impacts of the disaster, which may be potential (as in predictive identification) or existing (as in observational identification). Identification should encompass a broad space and time perspective, including impacts undergone (a) in the short, medium and long term and (b) in both primary and secondary effect areas. Thus, impact identification should therefore go beyond the reductionist view in which only the impacts associated with the most immediate time and space of the flood event are analysed. The function of SIA applied to FRM is precisely to extend the analysis to the grey areas of the disaster; that is, the spaces and times that are indirectly linked to its development but that are also de facto recipients of its consequences (e.g., the secondary spaces affected and the medium and long-term time scales). Additionally, due to the complex nature of social impacts, the identification process should adopt a long-term analytical view, sufficiently in-depth and holistic to encompass (a) intangible forms of effects, sometimes without physical-material foundation or ease of measurement, and (b) accumulative effect dynamics, in which already experienced impacts transform the living conditions of the exposure units, thereby in the last instance determining adaptive capacities for response to medium and long-term disaster impacts.

The complex nature of social impacts thus makes it necessary to articulate an integrated identification strategy combining different types of knowledge [91,133] and taking into account (a) the subjective nature of some impacts and (b) their technical and social complexity, which often requires highly specialised knowledge. Thus, identification should be carried in the following steps:

- Secondary data sources review: subject to availability, a primary data review of official sources should be made to ascertain the most immediate disaster impacts (e.g., preliminary assessment of damages), focusing on essential factors such as the number of fatalities or the extent of material and infrastructural damage. Additionally, this preliminary review should define the most and least affected social and territorial areas.

- Interviews with exposure units (experience): to embrace the subjective nature of impacts, semi-structured interviews with the social actors, gathering qualitative information on their experiences of the impacts, should be carried out. These interviews should be constructed on the basis of (a) a map of actors taken from the stakeholder analysis, and (b) a script based on the information from the baseline study.

- Interviews with decision-makers (responsibility) and third parties (interest): in this methodological proposal, this impact identification technique, based on the views of decision-makers and experts, is complementary. Some highly complex or long-term impacts are difficult to perceive and require specialised knowledge to be identified. To this end, and in order to complement the information gathered from the local community, the identification process should be completed through interviews with (a) decision-makers (e.g., authorities and institutional representatives, management 
specialists and emergency services), and (b) third parties (e.g., NGOs, water industry corporations and academic experts).

Lastly, since semi-structured interviews are oriented towards obtaining non-standardised, qualitative information, it should also be noted that identification is not always direct and explicit. Interviewees do not always consciously identify impacts, and neither do they express them in terms of an inventory. On the contrary, during the interviews some stakeholders give only colloquial, unsystematic accounts of their perceptions of the disaster. This obliges the SIA team to complement the process of identification. To this end the information is coded, converting it from its raw, unsystematised state into inductive codes yielding a uniform representation of the impacts. This should result in a list of social impacts, which may include a categorization of impact areas to facilitate systematization (Table 2). In line with the analysis of social impacts offered by the Associated Programme on Flood Management of the World Meteorological Organization [11], we should categorise the list of impacts according to the following classification:

- Loss of life and property: the immediate or short-term effects of the floods, among them the human victims, material damages, deterioration of the economic fabric and destruction or incapacitation of strategic infrastructures.

- Loss of livelihoods: the economic activities paralysed as a consequence of the human, material and infrastructural shock to the society and territory affected. The dislocation of everyday socio-economic circuits, together with the costs of repair and rehabilitation, may result in a loss and/or deterioration of goods and means of subsistence, which may then cause a fall in purchasing power, not only among directly affected individuals, but also among those belonging to the adjacent or secondarily affected areas that have experienced less or zero flooding. Various analysts $[93,102,103]$ have recommended semi-automated social media analytics for rapidly estimating direct flood damages and obtaining a basis for assessing other impacts.

- Migratory processes: migratory processes or population displacements towards other geographical points, either temporary or permanent. These secondary-effect enclaves, depending on the socio-territorial conditions, can undergo or experience worsening problems of irregular employment, saturation of urban space or pressure in the labour market, accompanied by the resulting risks of conflict between local and nonlocal populations.

- Psychosocial effects: when they suffer the entire range of impacts, individuals are exposed to the incapacitation of their social relationships on all levels. This dislocation of daily social life can cause psychological problems such as stress, anxiety and other types of emotional imbalance.

- Barriers to economic growth and development: depending on the level of socioeconomic development of the region affected by the disaster, impacts may become permanent in the society and territory, give rise to new socio-economic vulnerabilities and lead to a downturn in regional development. When flood events are recurrent and the accumulation of impacts comes into play, the effects on development can have a structural scope.

- Political consequences: reputational costs for political representatives in the form of loss of trust or support from part of the population due to the results of management of the before, during and after-disaster phases. 
Table 2. Example of a list of social impacts. This list should be completed with all identified impacts. Source: created by the authors.

\begin{tabular}{|c|c|c|}
\hline Impact Code & Category & Description \\
\hline A & Economic & $\begin{array}{c}\text { Economic and employment losses due to the interruption of economic activity in the } \\
\text { service sector }\end{array}$ \\
\hline B & Political & $\begin{array}{l}\text { Political disaffection among affected communities due to the lack of flood risk } \\
\text { management mechanisms }\end{array}$ \\
\hline $\mathrm{C}$ & Social & Forced resettlement of low-income population in houses at risk of collapse \\
\hline $\mathrm{D}$ & Cultural & Increased social awareness of risk and strengthening of the collective flooding memory \\
\hline $\mathrm{E}$ & Economic & $\begin{array}{c}\text { Loss of reputational value of the region as a safe tourist destination in the international } \\
\text { tourism market }\end{array}$ \\
\hline$(\ldots)$ & $(\ldots)$ & $(\ldots)$ \\
\hline
\end{tabular}

\subsubsection{Impact Assessment}

The objective of this phase of the SIA is to assess the complete set of impacts identified in the previous stage. In terms of assessment, the function of this methodological proposal is not to measure impacts but to analyse their characteristics exhaustively and in depth. The knowledge obtained from this assessment stage represents one of the main information inputs for formulating management options. This stage of the SIA adapted to FRM comprises two analytical procedures: (a) a multicriteria analysis and (b) a causal breakdown of impacts.

First, the list of impacts identified in the previous phase could be evaluated by means of a multicriteria analysis [91,134]. The objective of this analysis is to use the assessment criteria set out below in order to break down, describe and analyse the basic properties and characteristics of the impacts, in addition to their functions and behaviours throughout the space and time of their effects and the overall network of disaster impacts. To perform this multicriteria analysis, as well as deciding on a specific system of assessment matrix (e.g., Likert-type scale from 1 to 5), the following set of indicators or assessment criteria should be used (Table 3):

Table 3. Example of an impact assessment matrix. This matrix should be applied to each impact, including all criteria and affected stakeholders. Source: created by the authors.

\begin{tabular}{|c|c|c|c|c|c|c|c|}
\hline \multicolumn{8}{|c|}{$\begin{array}{l}\text { Impact A: Economic and Employment Losses due to the Interruption of Economic } \\
\text { Activity in the Service Sector }\end{array}$} \\
\hline Stakeholder Code & Nature & Intensity & Timescale & Duration & Reversibility & Conflict & $(\ldots)$ \\
\hline $\mathrm{A}$ & - & 2 & 3 & 2 & 4 & 2 & $(\ldots)$ \\
\hline B & - & 5 & 5 & 4 & 2 & 5 & $(\ldots)$ \\
\hline $\mathrm{C}$ & - & 3 & 4 & 3 & & 4 & $(\ldots)$ \\
\hline $\mathrm{D}$ & - & 4 & 3 & 3 & 3 & 3 & $(\ldots)$ \\
\hline $\mathrm{E}$ & $\mathrm{n}$ & - & - & - & - & - & $(\ldots)$ \\
\hline $\mathrm{F}$ & - & 1 & 4 & 1 & 5 & 2 & $(\ldots)$ \\
\hline$(\ldots)$ & $(\ldots)$ & $(\ldots)$ & $(\ldots)$ & $(\ldots)$ & $(\ldots)$ & $(\ldots)$ & $(\ldots)$ \\
\hline
\end{tabular}

- Recipient: the exposure unit undergoing the effects of the impact. This criterion is essential, since it enables us to establish the referential agent on which to base the evaluative meaning of the assessment and the other criteria. Thus, the criteria should be appraised by taking the conditions and adaptive capacities of a specific exposure unit as a reference point.

- Nature: the meaning of the effects (positive/+, negative/ - or neutral/n) experienced by the exposure unit of reference. 
- Intensity: the order of magnitude with which the impact affects, in a specified way, the exposure unit of reference.

- Source: the specific socio-territorial area to which the main inductive focus of the impact belongs.

- Responsibility: the institutional, individual or business actor responsible for managing the source or induction focus of the impact.

- Probability: the degree of probability of occurrence of the potential impacts that have not yet taken place in the course of the disaster cycle.

- Timescale: the periodicity of the appearance of the main potential impacts that have not yet occurred (short, medium or long term).

- Duration: the lifetime of the impact; that is, an estimate of the period from its appearance to its mitigation.

- Reversibility: the probability that the damage suffered by the affected unit will be dispelled, thus returning the unit to its original or pre-disaster state.

- Conflict potential: the degree of social tension arising between exposure units, decisionmakers and/or third parties as a consequence of the impact.

- Manageability: the room for action available for managing and mitigating the impact, or the viability of measures aimed to do this.

Due to the technical complexity of some of these criteria, the participatory impact assessment based on the exposure units' non-specialised knowledge may include biases, and as a result may not ensure sufficient validity. Thus, it is necessary to adopt a mixed-method approach in which (a) the exposure units, in addition to performing the identification, define the basic characteristics of the impact (its nature and intensity), and (b) the SIA team, on the basis of the knowledge of the impacts acquired during the overall process of the study, assumes the responsibility of assessing the rest of the impacts.

Once the impacts have been assessed, they are prioritized in order to establish a gradated ranking from low to high importance, as in the case of the analytic hierarchy process [135]. The benchmark of importance, far from being based on objective criteria, is determined by the axiological characteristics of the SIA; that is, by the ethical values underlying the assessment, which gives priority to (a) social groups and (b) post-disaster development decisions, oriented towards reconstruction (returning to a zero or pre-disaster state) or restructuring (correcting the failed elements of the social structure). Weighting criteria should be used to draw up the prioritization. The result of this process will be a prioritized list or impact ranking.

Second, a causal impact analysis should be carried out, particularly of those impacts previously defined as priorities. This consists in breaking down each of the causal factors in the generative modulatory process of the impact. While the criterion-based analysis allows us to determine the state and evolution of the impact, this latter analysis dissects the generative causes and enables us to identify and plan management measures with an effective scope. Following the information obtained in the social context analysis (Section 4.1.3), it is necessary to analyse: (a) the influence, (b) the causal weight, and (c) the provenance of each of the main variables which, on different levels, make up the causal schema of each of the impacts, and which are:

- Hazard: the hazardousness of the effect foci related to the impact analysed, essentially with regard to the space-time distribution of rainfall and flooding process.

- Exposure: the influence on the generation of the impact of the location and proximity of residential settlements and economic activities to the flooding areas.

- Vulnerability (local forces): the social, cultural and economic conditions and adaptive capacities that are available or not to respond to the impact analysed.

- Supralocal forces: in relation to the impact analysed, the regulatory/ideological macrostructures and the social, economic and political processes to which the conditions of social vulnerability and socio-spatial configuration of the territory respond. 


\subsection{Phase 4: Impact Management}

This phase consists of the proposal and evaluation of impact management measures for the flood disaster (Figure 6). In line with the proactive nature of this methodological proposal, all the knowledge on the social impacts gathered so far (lists of stakeholders, lists of impacts and assessment results) culminates in this phase of the SIA, oriented towards identifying the opportunities for intervention in managing the disaster impacts.

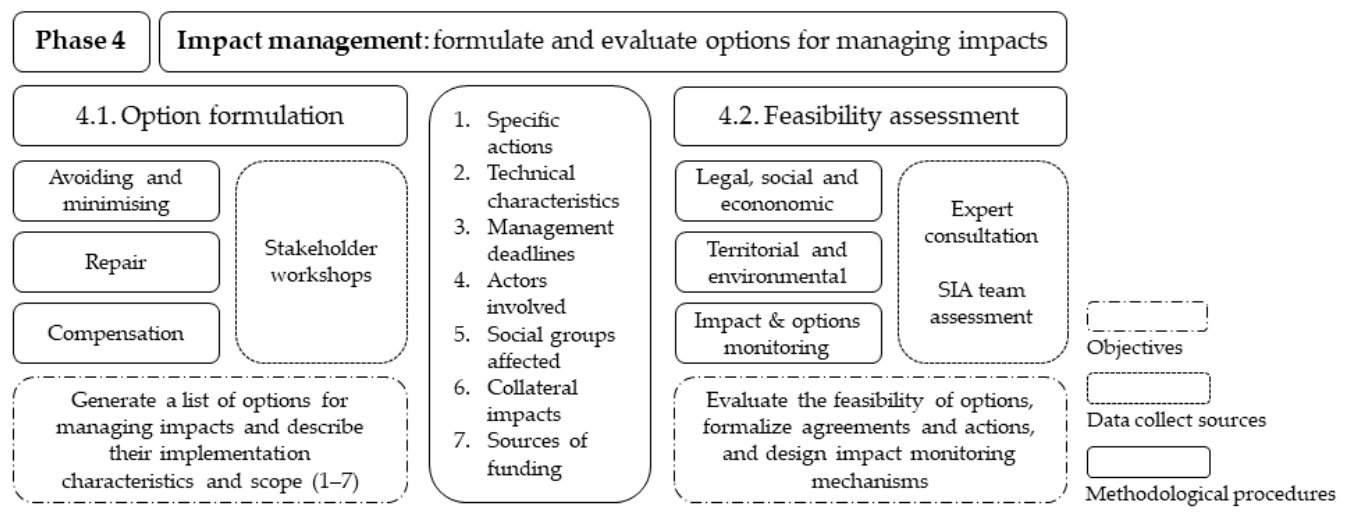

Figure 6. Methodological process of the impact management. Source: created by the authors.

\subsubsection{Option Formulation}

This stage of the SIA consists in setting up a mechanism for formulating management measures and actions to mitigate the disaster impacts. Depending on the phase of the disaster life cycle in which the SIA is carried out, on the feasibility of reaching agreements among stakeholders, and on the room for manoeuvre within the existing socio-territorial structures, the management options may have different degrees of mitigation [136], namely:

- Avoiding and minimising: for potential impacts of the disaster that have not yet taken place, measures aimed at transforming substantially or eliminating some risk foci in order to prevent impacts from appearing and developing (e.g., offering alternative housing and social assistance to people living in dwellings at risk of collapse due to the effects of flooding). This type of preventive measure can also be applied during the post-disaster phase to reduce the risk of disaster in future flood events.

- Repair: for impacts already caused, measures aimed at reconstituting the affected unit (e.g., the rehabilitation of affected housing, conforming to its original location and characteristics).

- Compensation: measures aimed exclusively at compensation through payments to affected people, unaccompanied by repairs of the affected units (e.g., economic compensation for those affected, without the possibility of recovering their homes or of having alternative housing).

In order to formulate options for the disaster impacts management, a second participatory process must be carried out with the stakeholders. This process may take the form of meetings or workshops with the main representatives of each of the three groups of stakeholders: the exposure units (residents' associations, ecologist groups, trade unions, etc.), decision-makers (political groups, institutional representatives of management bodies, etc.), and third parties (companies, NGOs, etc.). This participatory process, in addition to constituting an exercise of social communication around the already recognised impacts of the disaster, should set up a socially balanced negotiation of effective management measures that will (a) cover the priority impacts identified in the preceding phase and (b) use the descriptive knowledge (multicriteria analysis) and causal knowledge (causal analysis) previously produced to decide the characteristics and scope of the management measures. Franks and Vanclay [137] recommend taking nine key criteria into account to ensure the long-term validity of impact management measures: (1) producing an output (management plan) which systematically assembles the management mechanisms and 
enables them to be easily handled; (2) adapting measures to the lifecycle of the disaster and the long-term development of the social impacts; (3) setting up systems for classifying measures according to management priorities; (4) ensuring the engagement of interested parties, thereby fostering community participation in the proposal of management measures; (5) setting up means of reviewing the development of the impacts and carrying out their periodical reassessment; (6) ensuring coordination among different institutions, decision-makers and individuals; (7) promoting building capacities empowering stakeholders to address impacts and flood risks in general; (8) leaving a legacy for the future, encouraging decision-makers to plan measures that go beyond the disaster event itself and have a more global influence on management systems; and (9) forging connections between local and regional contexts, thus ensuring that the measures adopted can ameliorate not only local conditions but also regional processes determining social and institutional vulnerability to flood risks.

The option formulation process should be systematized through a matrix (Table 4), which, in addition to describing the options, provides information on the impacts and stakeholders affected by each option and indicates the phases of the disaster life cycle in which they take place.

Table 4. Example of a list of options. This list should include all identified options. Source: created by the authors.

\begin{tabular}{ccccc}
\hline Option Code & Disaster Phase & Target Stakeholder & Target Impact & Description of the Option \\
\hline A & Post & B, D, G & A, C & $\begin{array}{c}\text { Financial assistance for families directly } \\
\text { affected by job loss }\end{array}$ \\
\hline B & Pre & A, B, C, D, G & B, D, E & $\begin{array}{c}\text { Participatory development of a local } \\
\text { flood risk management plan }\end{array}$ \\
\hline C & Pre & A, C, F & E & $\begin{array}{c}\text { Creation of a "safe tourism seal" to } \\
\text { encourage companies in the sector to } \\
\text { develop flood emergency plans }\end{array}$ \\
\hline D & Post & B, G & C & $\begin{array}{c}\text { Public subsidies for resettled population } \\
\text { aimed at supplementing the payment of } \\
\text { rental costs }\end{array}$ \\
\hline$(\ldots)$ & $(\ldots)$ & $(\ldots)$ & $(\ldots)$ & $(\ldots)$
\end{tabular}

For this formulation process to be systematic and to encompass some of the previously mentioned criteria, each option should be described in detail, yielding information on:

- Specific actions: specific socio-territorial actions giving shape to the management measures.

- Technical characteristics: information on the dimensions and formats in which the management measures and actions will be realised.

- Management deadlines: time scale projections for the design and effective implementation of the measures and estimates of their duration.

- Actors involved: stakeholders responsible for promoting the design and the implementation of the measures and for carrying out and maintaining them.

- Social groups affected: social groups positively and negatively affected by the design and implementation of the management measures.

- Collaterally affected target impacts: impacts whose effects are increased or reduced secondarily due to the design and implementation of the measures.

- Sources of funding: public and/or private funding on local, regional, national or international levels available for financing the measures and actions.

\subsubsection{Option Assessment and Monitoring}

Once the management options are formulated and characterized, a feasibility assessment should be carried out by means of a multicriteria analysis $[57,134]$, evaluating the 
degree of viability of the design, execution and maintenance of the specific measures and actions from the following points of view (Table 5):

- Legal—institutional: legality, administrative processing, juridical security, political support and institutional viability.

- Economic: costs of the implementation and maintenance of the measures and their collateral effects (effects on other sectors).

- Territorial: coordination among the different territorial units comprising the disasteraffected area and adaptation of the demographic, infrastructural and natural conditions of the area.

- Environmental: damage to natural resources and flora and fauna, in addition to effects on ecosystem services and landscape value.

- Social: social legitimacy and acceptance of the measures and degree of consensus among the social actors involved.

Table 5. Example of option feasibility assessment. This matrix should include all identified options. Source: created by the authors.

\begin{tabular}{cccccc}
\hline Option Code & Legal & Economic & Territorial & Environmental & Social \\
\hline A & 4 & 3 & 5 & 5 & 5 \\
B & 3 & 3 & 3 & 4 & 2 \\
C & 2 & 4 & 3 & 4 & 3 \\
D & 4 & 2 & 3 & 3 & 5 \\
$(\ldots)$ & $(\ldots)$ & $(\ldots)$ & $(\ldots)$ & $(\ldots)$ & $(\ldots)$ \\
\hline
\end{tabular}

Lastly, this phase should include the design of monitoring mechanisms for the postSIA situation, aimed at (a) monitoring the development of the social impacts identified, both existing and potential; (b) analysing the way in which the effects produced by the impacts can reshape the adaptive conditions of the population; and (c) auditing the agreements on management measures in order to ensure their compliance. The monitoring method should be composed of indicators enabling the operationalization of the states of development of the impacts, agreements and situations of vulnerability, and, in the last instance, making the detection of unforeseen behaviours possible. These indicators should be underpinned by information taken from (a) secondary databases, (b) semi-structured interviews with key informants from the three main blocs of stakeholders, and (c) participant observation. Information should be reviewed and collected periodically, and this should be undertaken by a monitoring group or committee comprising different representatives of the main stakeholder groups. The monitoring systems, apart from detecting developmental anomalies, should include mechanisms and formulas for making fast and effective responses to the problems identified.

Finally, the SIA should conclude by compiling a final report on the results. The final report constitutes the tangible output or product bearing witness to the results of the research process in official written form, thus favouring the practical handling of the information and systematic regulation of the post-SIA situation.

\section{Conclusions}

To conclude this methodological approach to SIA in the FRM field, three reflections should be made on the challenges and opportunities involved in this adaptation. Firstly, it is necessary to bear in mind the exploratory nature of this proposal, made in the context of a new and developing field. Adapting an SIA for a planned intervention to an SIA of an environmental disaster requires a series of conceptual and methodological adjustments. While on the one hand planned interventions are of human origin, produce development effects and can be influenced by local communities through direct or indirect inclusion in decision-making on design, on the other hand environmental disasters result from the materialisation of natural hazards, mainly produce catastrophic damage, and the 
individuals or exposure units involved, although they may have adaptive capacities, have a more passive relationship to the unfolding of the disaster. These differential characteristics make it essential to design specific formulas and tools for identifying, assessing and managing the social impacts of flood disasters, and the methodological proposal presented here is one instance of this. This methodological proposal could be applied to other types of disasters, although this would probably require minor methodological and conceptual changes to adapt the tool to the particularities of other hazards. However, the application of this proposal to other areas should maintain the main goal of analysing social impacts holistically, as well as orienting the assessment towards the strategic management of impacts according to the logic of the disaster life cycle [138,139].

Secondly, in order to ease the integration of SIA into FRM, practitioners need to take on the role of educators when communicating the practical utility of this tool and explaining its technical handling. In this sense, this SIA proposal offers different FRM opportunities for policy makers, which materialize in the results obtained in each of the methodological phases. First, the baseline study provides the SIA with an exhaustive knowledge of the socio-environmental setting exposed to flood risk that allows a highly contextualized identification of impacts and management options. Secondly, the stakeholder analysis offers a mapping of the social actors involved in the experimentation and management of flood risk, as well as knowledge about the influence, the degree of exposure to the hazard and the adaptive capacities of each social actor. This information is handy to adjust the design of preparedness, response and recovery measures to the specific conditions and needs of the stakeholders at the social, economic, political and cultural levels, thus ensuring the high potential of the FRM strategies. Thirdly, the analysis of impacts provides an inventory of social impacts coded and classified by affected areas. This information can support a proactive and systematic control of the social effects of a disaster, thus avoiding the management of unforeseen impacts through less effective reactive response mechanisms. Likewise, the impact assessment matrix allows the decomposition of the characteristics of social impacts, offering strategic knowledge about their basic attributes, their social distribution, their spatio-temporal manifestation and their social and political assimilation. This detailed analysis of the characteristics of the social impacts contributes to the identification of measures specifically adapted to the particular way in which the different stakeholders experience each impact in terms of their magnitude and positive/negative nature. This specialised knowledge of the social, spatial and temporal distribution of impacts makes it possible to avoid the design of generic and decontextualized management measures. Fourth, the formulation of options for impact management is also accompanied by a detailed breakdown of the technical characteristics of the options, the actors involved and the mechanisms necessary for their design and implementation. This phase of the SIA includes a feasibility assessment matrix of the impact management options, through which it is possible to estimate the institutional, economic, environmental, territorial and social possibilities for their implementation. This knowledge allows a proactive management of the available options for managing impacts and helps to identify and strategically design the most potentially successful set of measures according to the conditions of the socio-territorial context. These results can be applied at any point in the life cycle of a disaster as an instrument of social innovation in systematic impact management. In the pre-event phase (preparedness), an SIA enables anticipation of the potential impacts of the disaster and supports the strategic design of preventive measures for strengthening the adaptive capacities of the population and reducing its exposure. In terms of improving the population's adaptive response, these preventive measures can include risk awareness actions, which can be promoted through participatory processes in order to promote knowledge of the environment and its risks, the population's adaptive proactivity to avoid individual behaviours of exposure to flooding areas, or knowledge of institutional mechanisms and ways of responding to risk. During the active phase of the event (response), an SIA enables us to systematically identify the direct and immediate effects of the disaster. This knowledge can favour the design of highly contextualised intervention procedures capable of supporting the selective mobilisation of 
resources and technical means towards critical areas identified by the SIA. Based on the knowledge provided by the SIA, the measures carried out during this phase may include actions for the effective communication of the flood event during the emergency process until the "return to normality", as well as the effective deployment of emergency services over critical socio-territorial areas or the strategic interruption of potentially problematic services and social activities. Finally, during the post-event phase (recovery), an SIA allows us to identify and assess the development of the impacts, anticipating their conversion into acquired vulnerabilities [16] and proposing measures for (a) mitigating their permanence in the society and territory in the medium and long terms, and (b) speeding up recovery processes in a socially and environmentally sustainable way and thus avoid social and territorial risks on the regional development dynamics. These measures, applied in accordance with the knowledge of the evolutionary dynamics of social impacts provided by the SIA, may include the strategic and socially oriented design of actions and aid for damage recovery, the organization of community disaster response strategies to promote proactive recovery from medium and long-term impacts, or the design of actions for public awareness and the promotion of flood collective memory.

Thirdly, it is necessary to reflect on the barriers that can hinder the effective transference of SIA to the FRM field. To this end, it is important to start from the mainly technocratic tradition of FRM institutions [140,141]. Although non-structural measures have made significant advances in recent decades, their implementation in FRM is still limited [142]. Among non-structural measures, those encompassing the social dimension of disasters are even less developed, since their presence in management plans is not only scarce but also normally superficial [143]. The minority character of the social dimension in FRM represents a challenge for the effective integration of SIA into the environmental disaster field. It is for this reason that the adaptation and consolidation of SIA in this area should be argued for and promoted as part of a transition towards an integrated management approach based on the combination of hard and soft measures and their application to a wide range of socio-territorial fields [144]. Thus, SIA represents an innovative management tool with the potential to (a) encompass the grey areas of the disaster (i.e., the most complex and intangible aspects of the life cycle of the disaster, which, despite being little explored, determine recovery processes in the medium and long term), and (b) propose and adapt the design of FRM measures to the real size and scope of the impacts, to social and economic needs and to existing institutional constraints. These characteristics frame SIA in the adaptive management paradigm, since it participates in the shift from an approach based on protecting and reacting (hazard control) to one aimed at adapting and preventing (risk management) [145]. However, adaptive approaches face institutional obstacles that hinder their implementation, namely [146]: (a) the administrative autonomy of the management organisms, which favours institutional isolation and slows down the incorporation of new measures; (b) the epistemological tradition of the decision-makers and management specialists, framed mainly in engineering approaches that are scarcely sensitive to the social dimension of the FRM; and (c) the authorities' desire to produce certainties to satisfy the population's expectations of total protection, which favours a lower acceptance of non-structural measures. Thus, the integration of SIA in the environmental disaster field should not only be based on its potentials as an applied tool in FRM, but also it is equally necessary for management organisms to take on the challenge of recognising the inherently complex nature of the social dimension of disasters and to accept that management mechanisms, rather than producing certainties, should be directed towards the proactive management of risk and its intrinsic levels of uncertainty.

Author Contributions: Conceptualization, P.A.-C., A.A., J.M.-M. and A.V.-R.; methodology, P.A.-C., A.A., J.M.-M. and A.V.-R.; investigation, P.A.-C., A.A., J.M.-M. and A.V.-R.; writing-original draft preparation, P.A.-C., A.A., J.M.-M. and A.V.-R.; writing-review and editing, P.A.-C., A.A., J.M.-M. and A.V.-R. All authors have read and agreed to the published version of the manuscript.

Funding: This research received no external funding. 
Acknowledgments: This study has been conducted within the grant received from the Programa Nacional de Formación de Profesorado Universitario (FPU) conceded by the Spanish Ministry of Universities to the first author. In the same way, the authors acknowledge the reviewers of the manuscript whose comments contributed greatly to improve this paper.

Conflicts of Interest: The authors declare no conflict of interest.

\section{References}

1. IPCC, Intergovernmental Panel on Climate Change. Managing the Risks of Extreme Events and Disasters to Advance Climate Change Adaptation; Field, C.B., Barros, V., Stocker, T.F., Qin, D., Dokken, D.J., Ebi, K.L., Mastrandrea, M.D., Mach, K.J., Plattner, G.K., Allen, S.K., et al., Eds.; Cambridge University Press: Cambridge, UK, 2012.

2. Hirabayashi, Y.; Mahendran, R.; Koirala, S.; Konoshima, L.; Yamazaki, D.; Watanabe, S.; Kanae, S. Global flood risk under climate change. Nat. Clim. Chang. 2013, 3, 816-821. [CrossRef]

3. Kundzewicz, Z.W.; Kanae, S.; Seneviratne, S.I.; Handmer, J.; Nicholls, N.; Peduzzi, P.; Muir-Wood, R. Flood risk and climate change: Global and regional perspectives. Hydrolog. Sci. J. 2014, 59, 1-28. [CrossRef]

4. Sofia, G.; Roder, G.; Dalla Fontana, G.; Tarolli, P. Flood dynamics in urbanised landscapes: 100 years of climate and humans' interaction. Sci. Rep. 2017, 7, 40527. [CrossRef]

5. EM-DAT, The OFDA/CRED International Disaster Database. Centre for Research on the Epidemiology of Disasters (CRED), Université Catholique de Louvain, Louvain. 2020. Available online: https:/ / www.emdat.be/ (accessed on 8 October 2020).

6. Petrucci, O. Assessment of the impact caused by natural disasters: Simplified procedures and open problems. In Approaches to Managing Disasters, Assessing Hazards, Emergencies and Disaster Impacts; Tiefenbacher, J.P., Ed.; INTECH: London, UK, 2012; pp. 109-132.

7. Winsemius, H.C.; Aerts, J.C.; Van Beek, L.P.; Bierkens, M.F.; Bouwman, A.; Jongman, B.; Ward, P.J. Global drivers of future river flood risk. Nat. Clim. Chang. 2016, 6, 381-385. [CrossRef]

8. Pardo, M.P.; Ortega, J. El impacto social del cambio climático: La metamorfosis social como ventana de oportunidad. In Informe España 2018; Blanco, A., Chueca, A.M., López-Ruiz, J.A., Mora, S., Eds.; Cátedra José María Martín Patino de la Cultura del Encuentro: Madrid, Spain, 2018; pp. 365-391.

9. Brouwer, R.; Schaafsma, M. Modelling risk adaptation and mitigation behaviour under different climate change scenarios. Clim. Change 2013, 117, 11-29. [CrossRef]

10. O'Donnell, E.C.; Thorne, C.R. Drivers of future urban flood risk. Philos. Trans. Royal Soc. Math. Phys. Eng. Sci. 2020, $378,20190216$. [CrossRef]

11. WMO, World Meteorological Organization. Integrated flood Management tools Series Public Perception of Flood Risk and Social Impact Assessment; Global Water Partnership and World Meteorological Organization: Stockholm, Sweden; Geneva, Switzerland, 2016.

12. Serje, M. Social relations: A critical reflection on the notion of social impacts as change. Environ. Impact Assess. Rev. 2017, 65, 139-146. [CrossRef]

13. Hammond, M.J.; Chen, A.S.; Djordjević, S.; Butler, D.; Mark, O. Urban flood impact assessment: A state-of-the-art review. Urban Water J. 2015, 12, 14-29. [CrossRef]

14. Blackman, D.; Nakanishi, H.; Benson, A.M. Disaster resilience as a complex problem: Why linearity is not applicable for long-term recovery. Technol. Forecast. Soc. Chang. 2017, 121, 89-98. [CrossRef]

15. Aznar-Crespo, P.; Aledo, A.; Melgarejo-Moreno, J. Social vulnerability to natural hazards in tourist destinations of developed regions. Sci. Total Environ. 2020, 709, 135870. [CrossRef]

16. Climent-Gil, E.; Aledo, A.; Vallejos-Romero, A. The social vulnerability approach for social impact assessment. Environ. Impact Assess. Rev. 2018, 73, 70-79. [CrossRef]

17. Orimoloye, I.R.; Belle, J.A.; Ololade, O.O. Exploring the emerging evolution trends of disaster risk reduction research: A global scenario. Int. J. Environ. Sci. Technol. 2020. [CrossRef]

18. Werritty, A. Sustainable flood management: Oxymoron or new paradigm? Area 2006, 38, 16-23. [CrossRef]

19. Kelman, I. Climate change and the Sendai framework for disaster risk reduction. Int. J. Disaster Risk Sci. 2015, 6, 117-127. [CrossRef]

20. Mondino, E.; Scolobig, A.; Borga, M.; Di Baldassarre, G. The Role of Experience and Different Sources of Knowledge in Shaping Flood Risk Awareness. Water 2020, 12, 2130. [CrossRef]

21. Sun, D.; Zhang, D.; Cheng, X. Framework of national non-structural measures for flash flood disaster prevention in China. Water 2012, 4, 272-282. [CrossRef]

22. Cools, J.; Innocenti, D.; O’Brien, S. Lessons from flood early warning systems. Environ. Sci. Policy 2016, 58, 117-122. [CrossRef]

23. Andor, M.A.; Osberghaus, D.; Simora, M. Natural disasters and governmental aid: Is there a charity hazard? Ecol. Econom. 2020, 169, 106534. [CrossRef]

24. Wahlström, M. New Sendai framework strengthens focus on reducing disaster risk. Int. J. Disaster Risk Sci. 2015, 6, $200-201$. [CrossRef]

25. Aitsi-Selmi, A.; Egawa, S.; Sasaki, H.; Wannous, C.; Murray, V. The Sendai framework for disaster risk reduction: Renewing the global commitment to people's resilience, health, and well-being. Int. J. Disaster Risk Sci. 2015, 6, 164-176. [CrossRef] 
26. Moe, T.L.; Pathranarakul, P. An integrated approach to natural disaster management. Disaster Prev. Manag. 2006, 15, 396-413. [CrossRef]

27. Kuhlicke, C.; Steinfuehrer, A.; Begg, C.; Bianchizza, C.; Bruendl, M.; Buchecker, M.; De Marchi, B.; Tarditti, M.D.M.; Hoeppner, C.; Komac, B.; et al. Perspectives on social capacity building for natural hazards: Outlining an emerging field of research and practice in Europe. Environ. Sci. Policy 2011, 14, 804-814. [CrossRef]

28. Wehn, U.; Rusca, M.; Evers, J.; Lanfranchi, V. Participation in flood risk management and the potential of citizen observatories: A governance analysis. Environ. Sci. Policy 2015, 48, 225-236. [CrossRef]

29. Challies, E.; Newig, J.; Thaler, T.; Kochskämper, E.; Levin-Keitel, M. Participatory and collaborative governance for sustainable flood risk management: An emerging research agenda. Environ. Sci. Policy 2016, 55, 275-280. [CrossRef]

30. Frigerio, I.; De Amicis, M. Mapping social vulnerability to natural hazards in Italy: A suitable tool for risk mitigation strategies. Environ. Sci. Policy 2016, 63, 187-196. [CrossRef]

31. Fernandez, P.; Mourato, S.; Moreira, M. Social vulnerability assessment of flood risk using GIS-based multicriteria decision analysis. A case study of Vila Nova de Gaia (Portugal). Geomat. Nat. Hazards Risk 2016, 7, 1367-1389. [CrossRef]

32. Blaikie, P.; Cannon, T.; Davis, I.; Wisner, B. At Risk: Natural Hazards, People's Vulnerability, and Disasters; Routledge: London, UK, 1994.

33. Kontar, Y.; Eichelberger, J.; Gavrilyeva, T.; Filippova, V.; Savvinova, A.; Tananaev, N.; Trainor, S. Springtime flood risk reduction in rural Arctic: A comparative study of interior Alaska, United States and Central Yakutia, Russia. Geosciences 2018, 8, 90-110. [CrossRef]

34. Mahmoudi, H.; Renn, O.; Vanclay, F.; Hoffmann, V.; Karami, E. A framework for combining social impact assessment and risk assessment. Environ. Impact Assess. Rev. 2013, 43, 1-8. [CrossRef]

35. Aerts, J.C.J.H.; Botzen, W.J.; Clarke, K.C.; Cutter, S.L.; Hall, J.W.; Merz, B.; Michel-Kerjan, E.; Mysiak, J.; Surminski, S.; Kunreuther, H. Integrating human behaviour dynamics into flood disaster risk assessment. Nat. Clim. Chang. 2018, 8, 193-199. [CrossRef]

36. Baldassarre, G.D.; Viglione, A.; Carr, G.; Kuil, L.; Salinas, J.; Blöschl, G. Socio-hydrology: Conceptualising human-flood interactions. Hydrol. Earth Syst. Sci. 2013, 17, 3295-3303. [CrossRef]

37. Gober, P.; Wheater, H.S. Debates-Perspectives on socio-hydrology: Modeling flood risk as a public policy problem. Water Resour Res. 2015, 51, 4782-4788. [CrossRef]

38. UNISDR, United Nations Office for Disaster Risk Reduction. Sendai Framework for Disaster Risk Reduction 2015-2030; United Nations: Geneva, Switzerland, 2015. Available online: http://www.unisdr.org/files/43291_sendaiframeworkfordrren.pdf (accessed on 8 October 2020).

39. World Bank. Analyzing the Social Impacts of Disasters; Global Facility for Disaster Reduction and Recovery: Washington, DC, USA, 2015.

40. Vanclay, F. International Principles for Social Impact Assessment. Impact. Assess. Proj. A 2003, 21, 5-11. [CrossRef]

41. The National Environmental Policy Act (NEPA) of 1969; Public Law 91-190:852-859.42, U.S.C. and as amended (P.L. $94-52$ and P.L. 94-83) 42 U.S.C. 4321-4347; United States Congress: Washington, DC, USA, 1970.

42. Finsterbusch, K. In praise of SIA-a personal review of the field of social impact assessment: Feasibility, justification, history, methods, issues. Impact Assess. 1995, 13, 229-252. [CrossRef]

43. Burdge, R.J.; Vanclay, F. Social impact assessment: A contribution to the state of the art series. Impact Assess. 1996, 14, 59-86. [CrossRef]

44. Howitt, R. Social impact assessment and resource development: Issues from the Australian experience. Aust. Geogr. 1989, 20, 153-166. [CrossRef]

45. Craig, D. Social impact assessment: Politically oriented approaches and applications. Environ. Impact Assess. Rev. 1990, 10, 37-54. [CrossRef]

46. Freudenburg, W.R. Social impact assessment. Annu. Rev. Sociol. 1986, 1, 451-478. [CrossRef]

47. Dietz, T. Theory and method in social impact assessment. Sociolo. Inq. 1987, 57, 54-69. [CrossRef]

48. Burdge, R.J.; Robertson, R.A. Social impact assessment and the public involvement process. Environ. Impact Assess. Rev. 1990, 10, 81-90. [CrossRef]

49. Burdge, R.J.; Vanclay, F. Social impact assessment. Environ. Soc. Impact Assess. 1995, 1, 31-66.

50. Vanclay, F. Social impact assessment. In Handbook of Environmental Impact Assessment; Petts, J., Ed.; Blackwell Science: Oxford, UK, 1999; pp. 301-326.

51. Esteves, A.M.; Franks, D.; Vanclay, F. Social impact assessment: The state of the art. Impact. Assess. Proj. A 2012, 30, 34-42. [CrossRef]

52. Vanclay, F.; Hanna, P. Conceptualizing company response to community protest: Principles to achieve a Social License to Operate. Land 2019, 8, 101. [CrossRef]

53. Vanclay, F. Reflections on Social Impact Assessment in the 21st century. Impact. Assess. Proj. A 2020, 38, 126-131. [CrossRef]

54. Aledo, A.; Domínguez-Gómez, J.A. Social Impact Assessment (SIA) from a multidimensional paradigmatic perspective: Challenges and opportunities. J. Environ. Manag. 2017, 195, 56-61. [CrossRef] [PubMed]

55. Gulakov, I.; Vanclay, F.; Arts, J. Modifying social impact assessment to enhance the effectiveness of company social investment strategies in contributing to local community development. Impact Assess. Proj. Apprais. 2020, 38, 382-396. [CrossRef] 
56. Imperiale, A.J.; Vanclay, F. Using Social Impact Assessment to Strengthen Community Resilience in Sustainable Rural Development in Mountain Areas. Mt. Res. Dev. 2016, 36, 431-442. [CrossRef]

57. Brouwer, R.; Van Ek, R. Integrated ecological, economic and social impact assessment of alternative flood control policies in the Netherlands. Ecol. Econom. 2004, 50, 1-21. [CrossRef]

58. Usman, R.A.; Olorunfemi, F.B.; Awotayo, G.P.; Tunde, A.M.; Usman, B.A. Disaster risk management and social impact assessment: Understanding preparedness, response and recovery in community projects. In Environmental Change and Sustainability; Silvern, S., Young, S., Eds.; IntechOpen: London, UK, 2013; pp. 259-274.

59. Allan, C.; Curtis, A.; Mazur, N. Understanding the Social Impacts of Floods in Southeastern Australia. Adv. Ecol. Res. 2006, 39, 159-174. [CrossRef]

60. Finucane, M.L.; Acosta, J.; Wicker, A.; Whipkey, K. Short-term solutions to a long-term challenge: Rethinking disaster recovery planning to reduce vulnerabilities and inequities. Int. J. Environ. Res. Public Health 2020, 17, 482. [CrossRef]

61. Liu, T.X.; Lu, Y.H.; Li, D.L.; Cheng, L. Social Impact Assessment for Post-disaster Reconstruction from International Finanocal Organization: A Case Study on World Bank's Wenchuan Earthquake Project. In New Thinking for Strategy: Green, Innovation and Sharing. In Proceedings of the International Conference on Strategic Management, Chengdu, China, 13-14 October 2017.

62. King, D. Organisations in disaster. Nat. Hazards 2007, 40, 657-665. [CrossRef]

63. Paveglio, T.B.; Brenkert-Smith, H.; Hall, T.; Smith, A.M. Understanding social impact from wildfires: Advancing means for assessment. Int. J. Wildland Fire 2015, 24, 212-224. [CrossRef]

64. Edgeley, C.M.; Paveglio, T.B. Community recovery and assistance following large wildfires: The case of the Carlton Complex Fire. Int. J. Disast. Risk Reduct. 2017, 25, 137-146. [CrossRef]

65. Sairinen, R. Social Impact Assessment for Environmental Disaster Management. In Building Safer Communities: Risk Governance, Spatial Planning, and Responses to Natural Hazards; Fra, U., Ed.; IOS Press: Amsterdam, The Netherlands, 2009 ; pp. $137-147$.

66. Cottrell, A.; King, D. Social assessment as a complementary tool to hazard risk assessment and disaster planning. Australas. J. Disaster Trauma Stud. 2010, 1, 1-15.

67. Dong, Z.H.; Zhang, J.Q.; Tong, Z.J.; Rong, A. Social impact assessment of grassland snow disasters in Xilingol League. J. Nat. Disasters 2016, 25, 59-68. [CrossRef]

68. De Risi, R.; De Paola, F.; Turpie, J.; Kroeger, T. Life Cycle Cost and Return on Investment as complementary decision variables for urban flood risk management in developing countries. Int. J. Disast. Risk Reduct. 2018, 28, 88-106. [CrossRef]

69. Benson, C.; Twigg, J.; Rossetto, T. Tools for Mainstreaming Disaster Risk Reduction: Guidance Notes for Development Organisations; ProVention Consortium: Geneva, Switzerland, 2007.

70. Vanclay, F.; Esteves, A.M. New Directions in Social Impact Assessment: Conceptual and Methodological Advances; Edward Elgar Publishing: Cheltenham, UK, 2011.

71. Kruger, L.; Sandham, L.A.; Van Niekerk, D. Optimizing SIA: Discourses in South African SIA and DRA practice. S. Afr. Geogr. J. 2020. [CrossRef]

72. Domínguez-Gómez, J.A. Four conceptual issues to consider in integrating social and environmental factors in risk and impact assessments. Environ. Impact Assess. Rev. 2016, 56, 113-119. [CrossRef]

73. Vanclay, F. Conceptualising social impacts. Environ. Impact Assess. Rev. 2002, 22, 183-211. [CrossRef]

74. Webler, T.; Kastenholz, H.; Renn, O. Public participation in impact assessment: A social learning perspective. Environ. Impact Assess. Rev. 1995, 15, 443-463. [CrossRef]

75. Becker, D.R.; Harris, C.C.; McLaughlin, W.J.; Nielsen, E.A. A participatory approach to social impact assessment: The interactive community forum. Environ. Impact Assess. Rev. 2003, 23, 367-382. [CrossRef]

76. O'Faircheallaigh, C. Public participation and environmental impact assessment: Purposes, implications, and lessons for public policy making. Environ. Impact Assess. Rev. 2010, 30, 19-27. [CrossRef]

77. Weidema, B. The integration of economic and social aspects in life cycle impact assessment. Int. J. Life Cycle Assess. 2006, 11, 89-96. [CrossRef]

78. Adger, W.N. Social vulnerability to climate change and extremes in coastal Vietnam. World Dev. 1999, 27, 249-269. [CrossRef]

79. Ward, P.S.; Shively, G.E. Disaster risk, social vulnerability, and economic development. Disasters 2017, 41, 324-351. [CrossRef]

80. Becker, S.L.; Reusser, D.E. Disasters as opportunities for social change: Using the multi-level perspective to consider the barriers to disaster-related transitions. Int. J. Disast. Risk Reduct. 2016, 18, 75-88. [CrossRef]

81. Lin, K.H.E.; Lee, H.C.; Lin, T.H. How does resilience matter? An empirical verification of the relationships between resilience and vulnerability. Nat. Hazards 2017, 88, 1229-1250. [CrossRef]

82. Ibarrarán, M.E.; Ruth, M.; Ahmad, S.; London, M. Climate change and natural disasters: Macroeconomic performance and distributional impacts. Environ. Dev. Sustain. 2009, 11, 549-569. [CrossRef]

83. Neumayer, E.; Plümper, T. The gendered nature of natural disasters: The impact of catastrophic events on the gender gap in life expectancy, 1981-2002. Ann. Am. Assoc. Geogr. 2007, 97, 551-566. [CrossRef]

84. Vanclay, F.; Esteves, A.M.; Aucamp, I.; Franks, D.M. Social Impact Assessment: Guidance for Assessing and Managing the Social Impacts of Projects; International Association for Impact Assessment: Fargo, ND, USA, 2015.

85. Domínguez-Gómez, J.A.; Aledo, A.; Mañas-Navarro, J.J. Historia y evolución de la EIS. In Evaluación de Impacto Social: Teoría, Método y Casos; Aledo, A., Domínguez-Gómez, J.A., Eds.; Publicacions de la Universitat d'Alacant: Alicante, Spain, 2019; pp. 17-31. 
86. Moher, D.; Shamseer, L.; Clarke, M.; Ghersi, D.; Liberati, A.; Petticrew, M.; Shekelle, P.; Stewart, L.A.; PRISMA-P Group. Preferred reporting items for systematic review and meta-analysis protocols (PRISMA-P) 2015 statement. Syst. Rev. 2015, 4, 1-9. [CrossRef] [PubMed]

87. Pereira, S.; Zêzere, J.L.; Quaresma, I.; Santos, P.P.; Santos, M. Mortality patterns of hydro-geomorphologic disasters. Risk Anal. 2016, 36, 1188-1210. [CrossRef] [PubMed]

88. Carrivick, J.L.; Tweed, F.S. A global assessment of the societal impacts of glacier outburst floods. Glob. Planet. Chang. 2016, 144, 1-16. [CrossRef]

89. Carroll, B.; Balogh, R.; Morbey, H.; Araoz, G. Health and social impacts of a flood disaster: Responding to needs and implications for practice. Disasters 2010, 34, 1045-1063. [CrossRef] [PubMed]

90. Rodriguez-Llanes, J.M.; Ranjan-Dash, S.; Mukhopadhyay, A.; Guha-Sapir, D. Looking upstream: Enhancers of child nutritional status in post-flood rural settings. PeerJ 2016, 4, e1741. [CrossRef]

91. Deshmukh, A.; Oh, E.H.; Hastak, M. Impact of flood damaged critical infrastructure on communities and industries. Built Environ. Proj. Asset Manag. 2011, 1, 156-175. [CrossRef]

92. Boulomytis, V.T.G.; Imteaz, M.A.; Zuffo, A.C.; Alves, C.D. Analysis of the urbanisation effects on the increase of flood susceptibility in coastal areas. Theor. Empir. Res. Urban Manag. 2016, 11, 30-45.

93. Zhang, C.; Yao, W.; Yang, Y.; Huang, R.; Mostafavi, A. Semiautomated social media analytics for sensing societal impacts due to community disruptions during disasters. Comput. Aided Civ. Inf. 2020, 35, 1331-1348. [CrossRef]

94. Lamond, J.E.; Joseph, R.D.; Proverbs, D.G. An exploration of factors affecting the long term psychological impact and deterioration of mental health in flooded households. Environ. Res. 2015, 140, 325-334. [CrossRef]

95. Trezzini, F.; Giannella, G.; Guida, T. Landslide and flood: Economic and social impacts in Italy. In Landslide Science and Practice; Canuti, P., Sassa, K., Margottini, C., Eds.; Springer: Heidelberg, Germany, 2013; pp. 171-176.

96. Alfieri, L.; Feyen, L.; Salamon, P.; Thielen, J.; Bianchi, A.; Dottori, F.; Burek, P. Modelling the socio-economic impact of river floods in Europe. Nat. Hazards Earth Syst. Sci. 2016, 16, 1401-1411. [CrossRef]

97. Denhart, H. Deconstructing disaster: Psycho-social impact of building deconstruction in Post-Katrina New Orleans. Cities 2009, 26, 195-201. [CrossRef]

98. Ha, K.M. Mitigating psychological impact: The experience of Korean disaster management. Community Ment. Health J. 2020. [CrossRef]

99. Albrecht, F. Natural hazard events and social capital: The social impact of natural disasters. Disasters 2018, 42, 336-360. [CrossRef] [PubMed]

100. Lee, J. The social impact of natural hazards: A multi-level analysis of disasters and forms of trust in mainland China. Disasters 2021, 45, 158-179. [CrossRef]

101. Supadli, I.; Saputri, A.; Mawengkang, H. Mitigating Local Natural Disaster through Social Aware Preparedness Using Complexity Approach. In IOP Conference Series: Materials Science and Engineering, Proceedings of the 4th International Conference on Operational Research (InteriOR), Medan, Indonesia, 21-23 August 2017; IOP Publishing: Bristol, UK, 2017.

102. Fan, C.; Jiang, Y.; Mostafavi, A. Social sensing in disaster city digital twin: Integrated textual-visual-geo framework for situational awareness during built environment disruptions. J. Manage. Eng. 2020, 36, 04020002. [CrossRef]

103. Pastor-Escuredo, D.; Torres, Y.; Martinez-Torres, M.; Zufiria, P.J. Rapid Multi-Dimensional Impact Assessment of Floods. Sustainability 2020, 12, 4246. [CrossRef]

104. Gurtner, Y.; Cottrell, A.; King, D. PRE E RAPID: Community Impact Assessment for Disaster Recovery; Centre for Disaster Studies, James Cook University: Townsville, Australia, 2011.

105. Simonović, P. Social criteria for evaluation of flood control measures: Winnipeg case study. Urban Water 1999, 2, 167-175. [CrossRef]

106. Aledo, A.; Domínguez-Gómez, J.A. Evaluación de Impacto Social: Teoría, Método y Casos; Publicacions de la Universitat d'Alacant: Alicante, Spain, 2019.

107. Aledo, A. Desigualdad y grandes obras públicas: La ampliación del Canal de Panamá. Portularia 2006, 6, 59-87.

108. Aledo, A. El socio-espacio de conflicto. Un marco conceptual para el análisis de los conflictos asociados a riesgos tecnológicos. In Riesgos, Gobernanza y Conflictos Socioambientales; Vallejos-Romero, A., Valencia, J., Boso, A., Eds.; Ediciones Universidad de la Frontera: Santiago de Chile, Chile, 2018; pp. 43-68.

109. Aledo, A.; García-Andreu, H.; Pinese, J. Using causal maps to support ex-post assessment of social impacts of dams. Environ. Impact Assess. Rev. 2015, 55, 84-97. [CrossRef]

110. Gerotto, G.; Pisano, V.; Demajorovic, J.; Aledo, A.; Santiago, A.L. Impacto social da mineração: Uma comparação entre a percepção da empresa ea da comunidade. Contextus. Revista Contemp. Econ. Gestão 2019, 17, 140-167. [CrossRef]

111. Vallejos-Romero, A.; Cordoves-Sánchez, M.; Jacobi, P.; Aledo, A. In transitions we trust? Understanding citizen, business, and public sector opposition to wind energy and hydropower in Chile. Energy Res. Soc. Sci. 2020, 67, 101508. [CrossRef]

112. Aledo, A.; Sulaiman, S.N. La incuestionabilidad del riesgo. Ambiente Soc. 2014, 17, 9-16. [CrossRef]

113. Aledo, A.; Sulaiman, S.N. La incuestionabilidad del riesgo: Vulnerabilidad social y riesgo sísmico en municipios turísticos. Cuad. Turismo 2015, 36, 17-37. [CrossRef]

114. Sulaiman, S.N.; Aledo, A. Desastres naturais: Convivência com o risco. Estud. Avançados 2016, 30, 11-23. [CrossRef] 
115. Aznar-Crespo, P.; Aledo, A. Seismic risk through social vulnerability: A methodological proposal for the evaluation of the seismic vulnerability on the coast of Alicante, Spain. WIT Trans. Built Environ. 2018, 179, 357-367.

116. Raška, P.; Dubišar, J. Impacts of natural hazards on an early industrial community: A case study of North Bohemia and its implications for long-term vulnerability assessment. Morav. Geogr. Rep. 2017, 25, 13-23. [CrossRef]

117. Raška, P.; Zábranský, V.; Dubišar, J. Using Documentary Data to Reconstruct Social Responses and Local-Based Adaptation Strategies to Landslide and Flood Hazards in N Czechia. In Engineering Geology for Society and Territory; Lollino, G., Giordan, D., Marunteanu, C., Christaras, B., Yoshinori, I., Margottini, C., Eds.; Springer: Cham, Switzerland, 2015; pp. 443-446. [CrossRef]

118. Djalante, R. A systematic literature review of research trends and authorships on natural hazards, disasters, risk reduction and climate change in Indonesia. Nat. Hazards Earth Syst. Sci. 2018, 18, 1785-1810. [CrossRef]

119. Tang, L.; Macdonald, N.; Sangster, H.; Chiverrell, R.; Gaulton, R. Reassessing long-term drought risk and societal impacts in Shenyang, Liaoning Province, north-east China (1200-2015). Clim. Past 2020, 16, 1917-1935. [CrossRef]

120. Erfurt, M.; Skiadaresis, G.; Tijdeman, E.; Blauhut, V.; Bauhus, J.; Glaser, R.; Schwarz, J.; Tegel, W.; Stahl, K. A multidisciplinary drought catalogue for southwestern Germany dating back to 1801. Nat. Hazards Earth Syst. Sci. 2020, 20, 2979-2995. [CrossRef]

121. Brunner, M.I.; Gilleland, E.; Wood, A.; Swain, D.L.; Clark, M. Spatial dependence of floods shaped by spatiotemporal variations in meteorological and land-surface processes. Geophys. Res. Lett. 2020, 47, e2020GL088000. [CrossRef]

122. Merz, B.; Thieken, A.H.; Gocht, M. Flood risk mapping at the local scale: Concepts and challenges. In Flood Risk Management in Europe; Stive, M.J.F., Hall, J.W., Begum, S., Eds.; Springer: Dordrecht, The Netherlands, 2007; pp. 231-251.

123. Kam, J.; Stowers, K.; Kim, S. Monitoring of drought awareness from google trends: A case study of the 2011-17 California drought. Weather Clim. Soc. 2019, 11, 419-429. [CrossRef]

124. Griffiths, H.M.; Tooth, S. Remembering and forgetting floods and droughts: Lessons from the Welsh colony in Patagonia. Cult. Geogr. 2020. [CrossRef]

125. Vinke-de Kruijf, J.; Kuks, S.M.; Augustijn, D.C. Governance in support of integrated flood risk management? The case of Romania. Environ. Dev. 2015, 16, 104-118. [CrossRef]

126. Mavhura, E. Analysing drivers of vulnerability to flooding: A systems approach. S. Afr. Geogr. J. 2019, 101, 72-90. [CrossRef]

127. Birkmann, J.; Cardona, O.D.; Carreno, M.L.; Barbat, A.H.; Pelling, M.; Schneiderbauer, S.; Kienberger, S.; Keiler, M.; Alexander, D.C.; Zeil, P.; et al. Framing vulnerability, risk and societal responses: The MOVE framework. Nat. Hazards 2013, 67, 193-211. [CrossRef]

128. Rufat, S.; Tate, E.; Burton, C.G.; Maroof, A.S. Social vulnerability to floods: Review of case studies and implications for measurement. Int. J. Disast. Risk Reduct. 2015, 14, 470-486. [CrossRef]

129. Coleman, N.; Esmalian, A.; Mostafavi, A. Anatomy of susceptibility for shelter-in-place households facing infrastructure service disruptions caused by natural hazards. Int. J. Disast. Risk Reduct. 2020, 50, 101875. [CrossRef]

130. Hooli, L.J. Resilience of the poorest: Coping strategies and indigenous knowledge of living with the floods in Northern Namibia. Reg. Environ. Chang. 2016, 16, 695-707. [CrossRef]

131. Thieken, A.H.; Kienzler, S.; Kreibich, H.; Kuhlicke, C.; Kunz, M.; Mühr, B.; Müller, M.; Otto, A.; Petrow, T.; Pisi, S.; et al. Review of the flood risk management system in Germany after the major flood in 2013. Ecol. Soc. 2016, 21. [CrossRef]

132. Himes-Cornell, A.; Ormond, C.; Hoelting, K.; Ban, N.C.; Koehn, J.Z.; Allison, E.H.; Larson, E.C.; Monson, D.H.; Huntington, H.P.; Okey, T.A. Factors affecting disaster preparedness, response, and recovery using the community capitals framework. Coast. Manag. 2018, 46, 335-358. [CrossRef]

133. Irvine, G.; Pauli, N.; Varea, R.; Boruff, B. A participatory approach to understanding the impact of multiple natural hazards in communities along the Ba River, Fiji. In Climate-Induced Disasters in the Asia-Pacific Region: Response, Recovery, Adaptation; Pauli, N., Neef, A., Eds.; Emerald Publishing Limited: Bradford, UK, 2020; pp. 57-86. [CrossRef]

134. Sanabria, N.; Valentin, V. A Hybrid Integrated Assessment for the Selection of Flood Mitigation Alternatives. Constr. Res. Congr. 2016, 1, 1413-1423. [CrossRef]

135. Lee, H.C. Integrated assessment method for the flood management project in Taiwan. Disaster Adv. 2011, 4, 45-52.

136. João, E.; Vanclay, F.; den Broeder, L. Emphasising enhancement in all forms of impact assessment: Introduction to a special issue. Impact. Assess. Proj. A 2011, 29, 170-180. [CrossRef]

137. Franks, D.M.; Vanclay, F. Social Impact Management Plans: Innovation in corporate and public policy. Environ. Impact Assess. Rev. 2013, 43, 40-48. [CrossRef]

138. Urban, R.; Hoskova-Mayerova, S. Threat life cycle and its dynamics. Deturope 2017, 9, 93-109.

139. Potůček, R. Life cycle of the crisis situation threat and its various models. In Qualitative and Quantitative Models in Socio-Economic Systems and Social Work; Sarasola, J.L., Maturo, F., Hoskova-Mayerova, S., Eds.; Springer: Cham, Switzerland, 2020; pp. 443-461. [CrossRef]

140. Brown, J.D.; Damery, S.L. Managing flood risk in the UK: Towards an integration of social and technical perspectives. Trans. Inst. Br. Geogr. 2002, 27, 412-426. [CrossRef]

141. Teisman, G.; van Buuren, A.; Edelenbos, J.; Warner, J. Water governance: Facing the limits of managerialism, determinism, water-centricity, and technocratic problem-solving. Int. J. Water Gov. 2013, 1, 1-11. [CrossRef]

142. Shah, M.A.R.; Rahman, A.; Chowdhury, S.H. Challenges for achieving sustainable flood risk management. J. Flood Risk Manag. 2018, 11, S352-S358. [CrossRef] 
143. Olcina-Sala, A.; Ortiz, G.; Aznar-Crespo, P. Evaluación de la integración de la dimensión social y la participación pública en los planes de gestión del riesgo de inundación: ¿cambio o continuidad paradigmática? In Riesgo de Inundación en España: Análisis y Soluciones Para la Generación de Territorios Resilientes; López-Ortiz, M.I., Melgarejo-Moreno, J., Eds.; Publicacions de la Universitat d'Alacant: Alicante, Spain, 2020; pp. 1283-1292.

144. Van Herk, S.; Rijke, J.; Zevenbergen, C.; Ashley, R. Understanding the transition to integrated flood risk management in the Netherlands. Environ. Innov. Soc. Transit. 2015, 15, 84-100. [CrossRef]

145. Burby, R.J. Hurricane Katrina and the paradoxes of government disaster policy: Bringing about wise governmental decisions for hazardous areas. Ann. Am. Acad. Political Soc. Sci. 2006, 604, 171-191. [CrossRef]

146. Van Buuren, A.; Lawrence, J.; Potter, K.; Warner, J.F. Introducing adaptive flood risk management in England, New Zealand, and the Netherlands: The impact of administrative traditions. Rev. Policy Res. 2018, 35, 907-929. [CrossRef] 